\title{
Supporting Information for: \\ De Novo Synthesis of Stable Tetrahydroporphyrinic Macrocycles: \\ Bacteriochlorins and a Tetradehydrocorrin
}

\author{
Han-Je Kim and Jonathan S. Lindsey
}

\section{Table of Contents}

1. General experimental section $\quad$ S1-S1

$\begin{array}{ll}\text { 2. NMR characterization } & \text { S1-S2 }\end{array}$

3. Optical spectral measurements $\quad$ S3-S3

4. Spectral data for selected compounds $\quad$ S4-S33

1. General. ${ }^{1} \mathrm{H}$ NMR (400 MHz) and ${ }^{13} \mathrm{C}$ NMR (100 MHz) spectra were collected at room temperature in $\mathrm{CDCl}_{3}$. Absorption spectra were collected in toluene at room temperature unless noted otherwise. Melting points are uncorrected. Column chromatography was performed with flash silica or alumina (80-200 mesh). Bacteriochlorins were analyzed in neat form by laser desorption mass spectrometry (LD-MS) in the absence of a matrix. The $\mathrm{CHCl}_{3}$ contained $0.8 \%$ ethanol.

2. NMR Characterization. A complete assignment of the resonances in the ${ }^{1} \mathrm{H}$ NMR spectra of hydroporphyrinic macrocycles is important for characterization as well as analysis of subsequent derivatization processes. All meso and $\beta$-protons for H-BC, MeO-BC, and TDC were assigned by NMR spectroscopy (HH-COSY and NOESY; $300 \mathrm{MHz}$ or $400 \mathrm{MHz}$ ). Generally the ${ }^{1} \mathrm{H}-\mathrm{NMR}$ spectra of the hydroporphyrins (H-BC, MeO-BC, and TDC) showed a singlet for each of the meso protons and a doublet (due to coupling with the neighboring pyrrolic $\mathrm{NH}$ proton) for each of the pyrrolic $\beta$-protons.

H-BC. The bacteriochlorin H-BC presents a relatively straightforward ${ }^{1} \mathrm{H}$ NMR spectrum with only nine resonances. On the basis of the nominal $C_{2 h}$ symmetry of $\mathbf{H}-\mathbf{B C}$, the typical chemical shifts of porphyrinic macrocycles, and NOE measurements, the three peaks above $\delta 8.50 \mathrm{ppm}$ are assigned as meso- or $\beta$-protons. The positions of the ortho- and metaprotons of the $p$-tolyl group were confirmed by COSY and NOESY. The resonance at $7.59 \mathrm{ppm}$ (meta-protons gave a strong NOE with that at $2.61 \mathrm{ppm}$ (methyl unit of the $p$-tolyl group). The singlet at $\delta 8.86 \mathrm{ppm}$ (most downfield peak, assigned to $\mathrm{H}^{10}$ and $\mathrm{H}^{20}$ ) showed a strong NOE with the singlet at $\delta 1.93 \mathrm{ppm}$ (assigned to the geminal-dimethyl group). The singlet at $\delta 8.81 \mathrm{ppm}$, which shows a strong NOE with the singlet at $4.46 \mathrm{ppm}$ stemming from the methylene $\left(\mathrm{CH}_{2}\right)$ group, is assigned to $\mathrm{H}^{5}$ and $\mathrm{H}^{15}$. The doublet at $\delta 8.13 \mathrm{ppm}$ from the ortho-protons of the $p$-tolyl group showed a strong NOE with the doublet (due to coupling with the neighboring pyrrolic $\mathrm{NH}$ proton) at $\delta 8.73 \mathrm{ppm}$, which results in assignment of this latter set of resonances to $\mathrm{H}^{3}$ and $\mathrm{H}^{13}$. In summary, all protons were unambiguously assigned.

MeO-BC. The bacteriochlorin MeO-BC presents a slightly more complex ${ }^{1} \mathrm{H}$ NMR spectrum versus that of $\mathbf{H}$-BC owing to the nominal $C_{s}$ symmetry. Unlike $\mathbf{H}$-BC, the two $p$-tolyl groups are not equivalent, the $\mathrm{H}^{10}$ and $\mathrm{H}^{20}$ protons are not equivalent, $\mathrm{H}^{3}$ and $\mathrm{H}^{13}$ are not equivalent, the gem-dimethyl groups are not equivalent, and so forth. Accordingly, the two NH protons $(\delta-1.90$ and $-1.78 \mathrm{ppm})$, the pair of geminal-dimethyl groups ( $\delta 1.91$ and $1.92 \mathrm{ppm})$, and the methylene unit in each of the pyrroline rings ( $\delta 4.40$ and $4.41 \mathrm{ppm})$ are non-equivalent 
and appear as distinct singlets. Each $p$-tolyl group gives a pair of doublets $(J=8.0,8.4 \mathrm{~Hz}$ in each case) in the region of $\delta 7.56-7.59 \mathrm{ppm}$ and $8.09-8.15 \mathrm{ppm}$. The five peripheral protons (3, $10,13,15$, and 20 positions) give rise to apparent singlets $(\delta 8.68,8.78$, and $8.81 \mathrm{ppm})$, a doublet ( $\delta 8.94 \mathrm{ppm}$ ), and a partially overlapping peak at $\delta 8.67 \mathrm{ppm}$.

The $p$-tolyl aryl resonances were readily identifiable (but not unambiguously assignable) by the characteristic doublets in the region of $\delta 7.55-8.17 \mathrm{ppm}$. Assignments of the orthoversus meta-protons of the two distinguishable $p$-tolyl groups were confirmed by NOESY with the $p$-methyl groups, given that the meta-protons gave a strong NOE with the methyl unit of the $p$-tolyl group. The peak at $\delta 4.49$ ppm gave a strong NOE with the most downfield doublet $(\delta$ $8.95 \mathrm{ppm}$ ), which led to the assignment of the former as the 5-methoxy group and the latter as the $\beta$-proton $\mathrm{H}^{3}$. The singlet at $\delta 4.41 \mathrm{ppm}$ gave a NOE with one of the partially overlapped peaks in the region of $\delta 8.66-8.68 \mathrm{ppm}$, resulting in assignment of the former to the 17methylene group and the latter to $\mathrm{H}^{15}$. The resonances from the two sets of ortho-protons showed NOEs with $\mathrm{H}^{3}$ and the three singlets at $\delta 8.81,8.78$, and $8.67 \mathrm{ppm}$ attributed to $\mathrm{H}^{20}, \mathrm{H}^{10}$, and $\mathrm{H}^{13}$. The NOE between the two peaks due to the geminal-dimethyl groups $(\delta 1.89-1.93$ ppm) and the resonances due to two meso protons led to unambiguous assignment of the $\mathrm{H}^{10}$ and $\mathrm{H}^{20}$ protons. In summary, all protons except the inner $\mathrm{NH}$ were unambiguously assigned.

TDC. The ${ }^{1} \mathrm{H}$ NMR spectrum showed relatively complex features owing to the lack of symmetry $\left(C_{1}\right)$ of TDC. The pair of geminal-dimethyl groups gives rise to four apparent singlets $(\delta 1.04,1.24,1.26$, and $1.33 \mathrm{ppm})$. The four protons of the methylene units in the pyrroline rings appear as pairs of doublets (AB pattern) at $\delta 1.82$ and $2.49 \mathrm{ppm}\left({ }^{2} J=13.2 \mathrm{~Hz}\right)$, and $\delta 2.65$ and $2.71 \mathrm{ppm}\left({ }^{2} J=18.8 \mathrm{~Hz}\right)$, respectively. The methine proton of the acetal unit gives a singlet at $\delta$ $4.26 \mathrm{ppm}$. Of the five protons at the perimeter, three give singlets $(\delta 5.42,5.43$, and $6.02 \mathrm{ppm})$ whereas the other two protons give doublets (due to coupling with the neighboring pyrrolic $\mathrm{NH}$ proton) at $\delta 6.25$ and $6.57 \mathrm{ppm}$. The aryl hydrogens of the $p$-tolyl groups give two pairs of doublets at $\delta 7.20 \mathrm{ppm}$ and $7.29 \mathrm{ppm}$, and at $\delta 7.38 \mathrm{ppm}$ and $8.42 \mathrm{ppm}$. The two NH protons exhibit two broad peaks in the region of $\delta 11.34-11.40 \mathrm{ppm}$ and $\delta 11.89-11.96 \mathrm{ppm}$. The downfield shift of the NH peaks is in sharp contrast to the resonance at $\sim \delta-1-3$ ppm of aromatic porphyrinic compounds.

More definitive assignments were obtained through use of COSY and NOESY experiments. The assignments of the two sets of ortho- versus meta-protons of the $p$-tolyl groups were confirmed by COSY and NOESY. A resonance at $\delta 2.62-2.74 \mathrm{ppm}$ gave an NOE with a singlet at $\delta 5.43 \mathrm{ppm}$; the former was assigned to the methylene group at the 12-position while the latter was assigned to $\mathrm{H}^{10}$. A set of peaks at $\delta 1.04$ and $1.33 \mathrm{ppm}$ gave an NOE with a singlet at $\delta 5.42 \mathrm{ppm}$, resulting in the former being assigned to the diastereotopic geminal methyl groups at the 3-position while the latter is assigned to $\mathrm{H}^{5}$. The resonances from a set of ortho-protons from a $p$-tolyl group gave an NOE with a doublet at $\delta 6.25 \mathrm{ppm}$ and a singlet at $\delta 6.02 \mathrm{ppm}$; the ortho-protons were assigned to the $p$-tolyl group at the 17-position while the latter peaks were assigned to $\mathrm{H}^{18}$ and $\mathrm{H}^{15}$, respectively. The resonances from the other set of ortho-protons gave an NOE with $\mathrm{H}^{5}$ and a doublet at $\delta 6.57 \mathrm{ppm}$. The latter is assigned to $\mathrm{H}^{8}$. Further NOE measurements with resonances from the ortho-protons identified the $\mathrm{H}^{8}$ and $\mathrm{H}^{18}$ protons.

The two faces of the macrocycle of TDC are not equivalent given the stereocenter at $\mathrm{C}^{1}$, the site of the AD-ring junction that bears the dimethyl acetal moiety. The two faces are designated as $\alpha$ and $\beta$, where $\alpha$ is the face on which the acetal group is positioned. The singlet at $4.26 \mathrm{ppm}$ (assigned to the $\mathrm{CH}$ moiety bearing the two methoxy groups) gave an NOE with a 
doublet at $\delta 2.49 \mathrm{ppm}$, which is assigned to $\mathrm{H}^{2} \alpha$. The resonance at $1.82 \mathrm{ppm}$ is thus assigned to $\mathrm{H}^{2} \beta$. The doublet stemming from $\mathrm{H}^{2} \alpha$ gave an NOE with the resonance at $\delta 1.33 \mathrm{ppm}$ attributed to a methyl group. Accordingly, the latter methyl group must be positioned on the same face $(\alpha)$ of the macrocycle. The resonance at $1.04 \mathrm{ppm}$ is then assigned to the $\beta-\mathrm{CH}_{3}$ group at the $\mathrm{C}^{3}$ position.

In summary, all protons except the inner $\mathrm{NH}$ were unambiguously assigned. The stereochemistry of the protons in ring A relative to the position of the $\mathrm{C}^{1}$-acetal were assigned. However, the stereochemistry of each of the protons in the opposing pyrroline unit (ring $\mathrm{C}$ ) was not assigned.

3. Optical Spectral Measurements. Molar Absorption Coefficients. The molar absorption coefficients were determined by dissolving a known quantity of each hydroporphyrin $(\sim 6 \mathrm{mg})$ in $100 \mathrm{~mL}$ of toluene. Then a known amount $(\sim 100 \mu \mathrm{L})$ of this solution was added to a quartz cuvette containing $3.0 \mathrm{~mL}$ of toluene. The absorption spectrum was recorded at room temperature.

Fluorescence Quantum Yields $\left(\boldsymbol{\Phi}_{\mathrm{f}}\right)$. The $\Phi_{\mathrm{f}}$ values were determined with bacteriochlorin samples in toluene at room temperature. The maximal absorption of each sample was $\sim 0.1$ both in the B-band region and in the $\mathrm{Q}_{\mathrm{y}}$ region, ensuring homogeneous illumination at $\lambda_{\mathrm{exc}}(373 \mathrm{~nm})$ and avoidance of the inner filter effect by the $\mathrm{Q}_{\mathrm{y}}$ band upon emission. Chlorophyll $a$ was chosen as a reference compound because chlorophyll $a$ has the following features: (i) significant absorption at $373 \mathrm{~nm}$ (blue shoulder of the B-band), (ii) emission in the red region (650-750 nm) with reasonable quantum efficiency $\left(\Phi_{\mathrm{f}}=0.325\right.$ in benzene $\left.{ }^{45}\right)$, (iii) ready availability, (iv) solubility in toluene, and (v) a sizable body of data is available concerning the fluorescence properties. All samples were degassed briefly prior to illumination. Excitation was performed using 0.5-mm excitation and emission slits ( 2 $\mathrm{nm}$ spectral bandwidth), 1-nm steps, and 0.1 $\mathrm{sec} / \mathrm{nm}$ integration time. Integrated fluorescence emission spectra were obtained with correction for detection-system spectral response and temporal variation in light intensity. The integrated spectra were corrected for absorption and the resulting value was ratioed to the known $\Phi_{\mathrm{f}}$ for chlorophyll $a$ to determine the $\Phi_{\mathrm{f}}$ values for the bacteriochlorins. Chlorophyll $a$ was found to have $\Phi_{\mathrm{f}}=0.35$ in toluene. The bacteriochlorins also were examined with $\lambda_{\mathrm{exc}}=351 \mathrm{~nm}$, affording identical results as upon $\lambda_{\mathrm{exc}}=373 \mathrm{~nm}\left(\mathbf{H}-\mathbf{B C}, \Phi_{\mathrm{f}}=0.14 ; \mathbf{M e O}-\mathbf{B C}, \Phi_{\mathrm{f}}=0.18\right)$. 


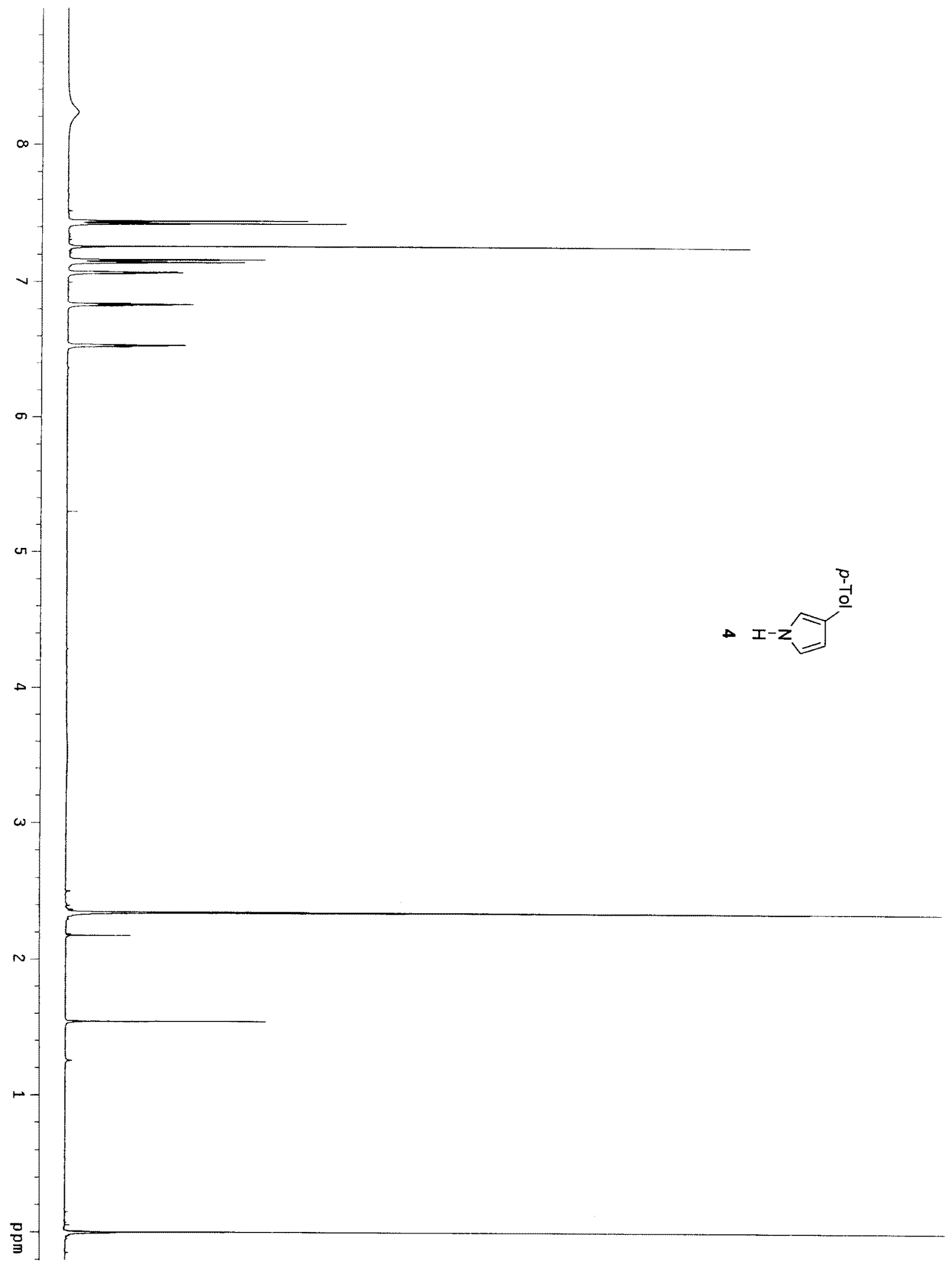




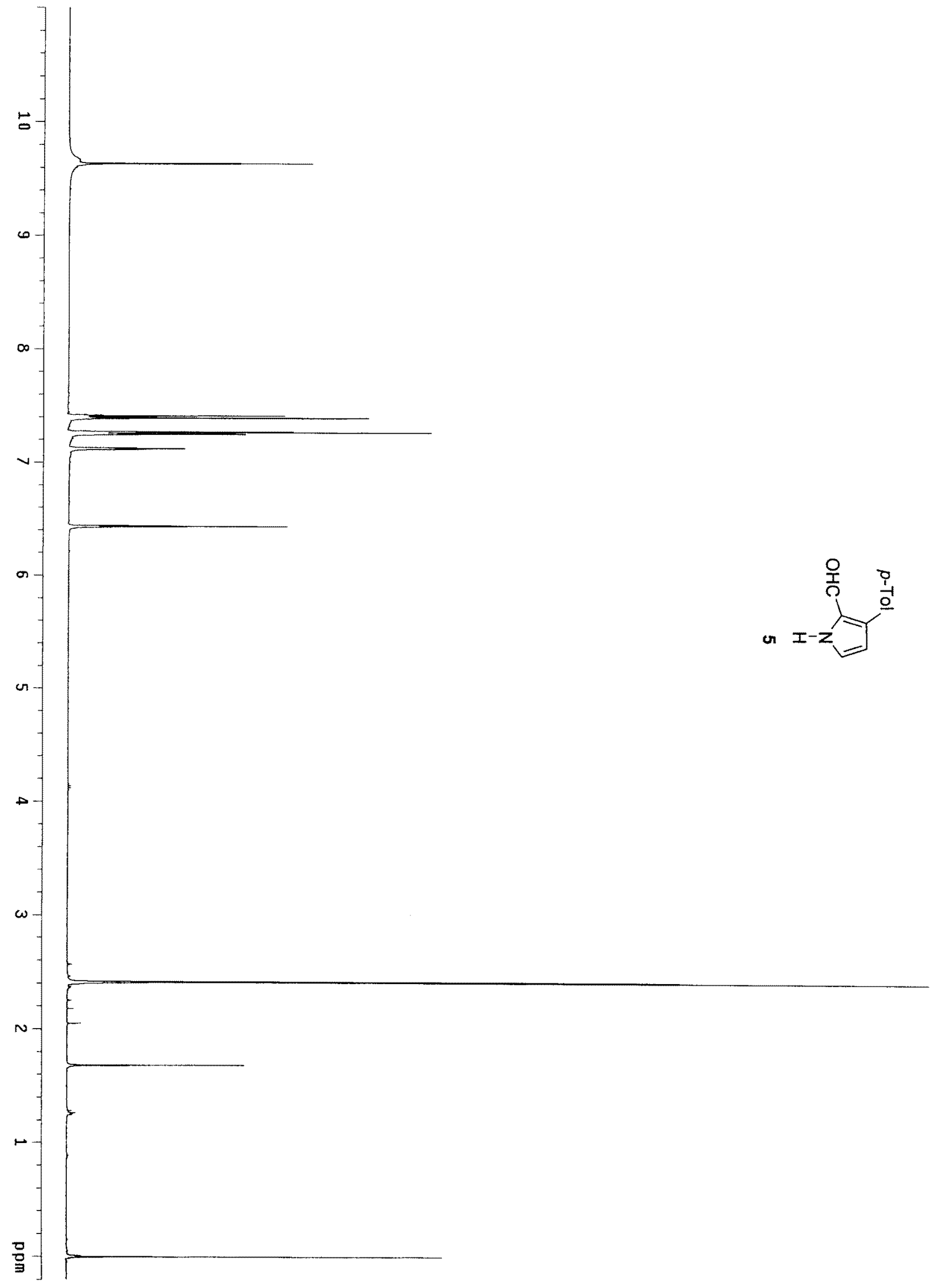




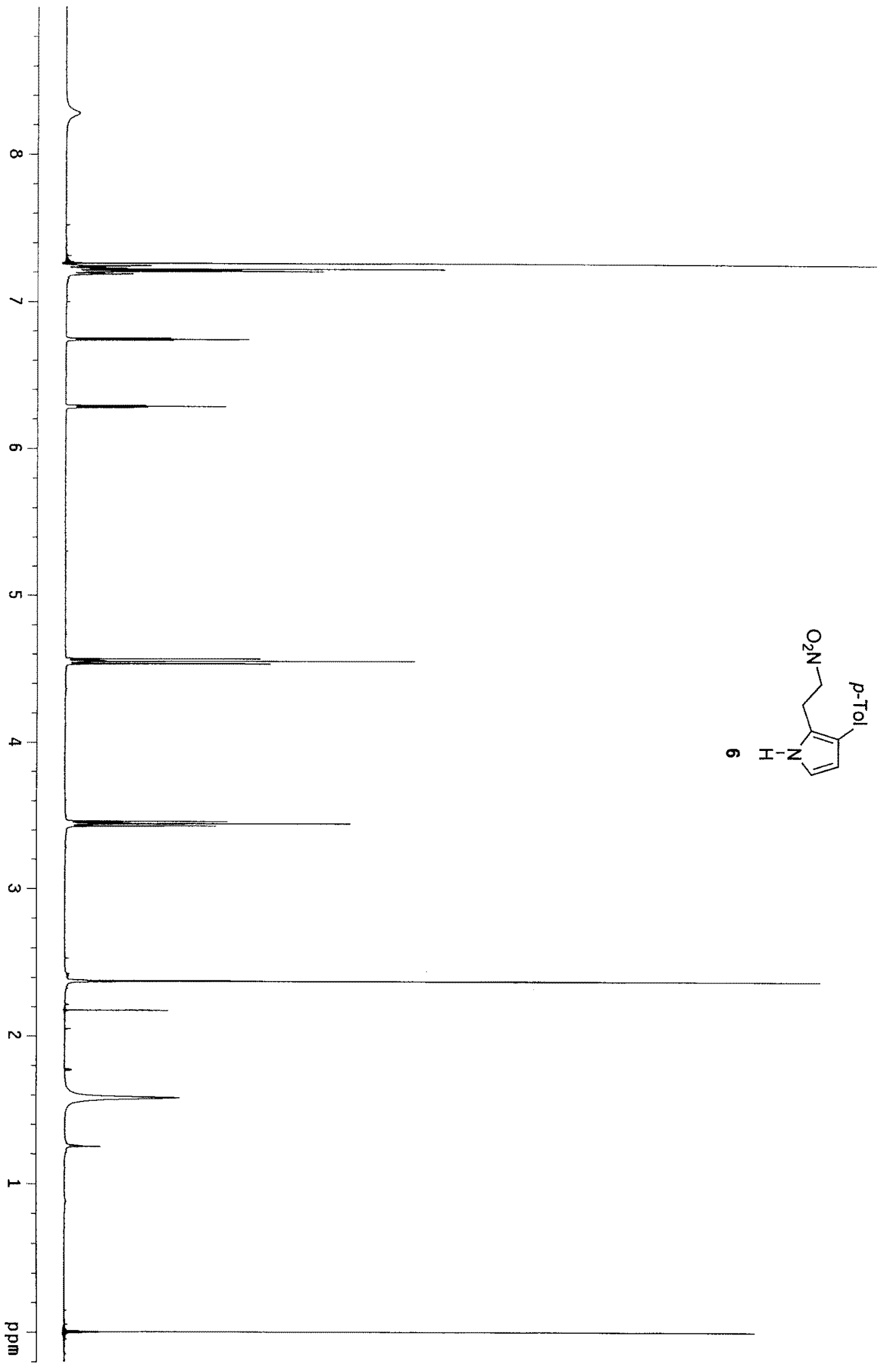




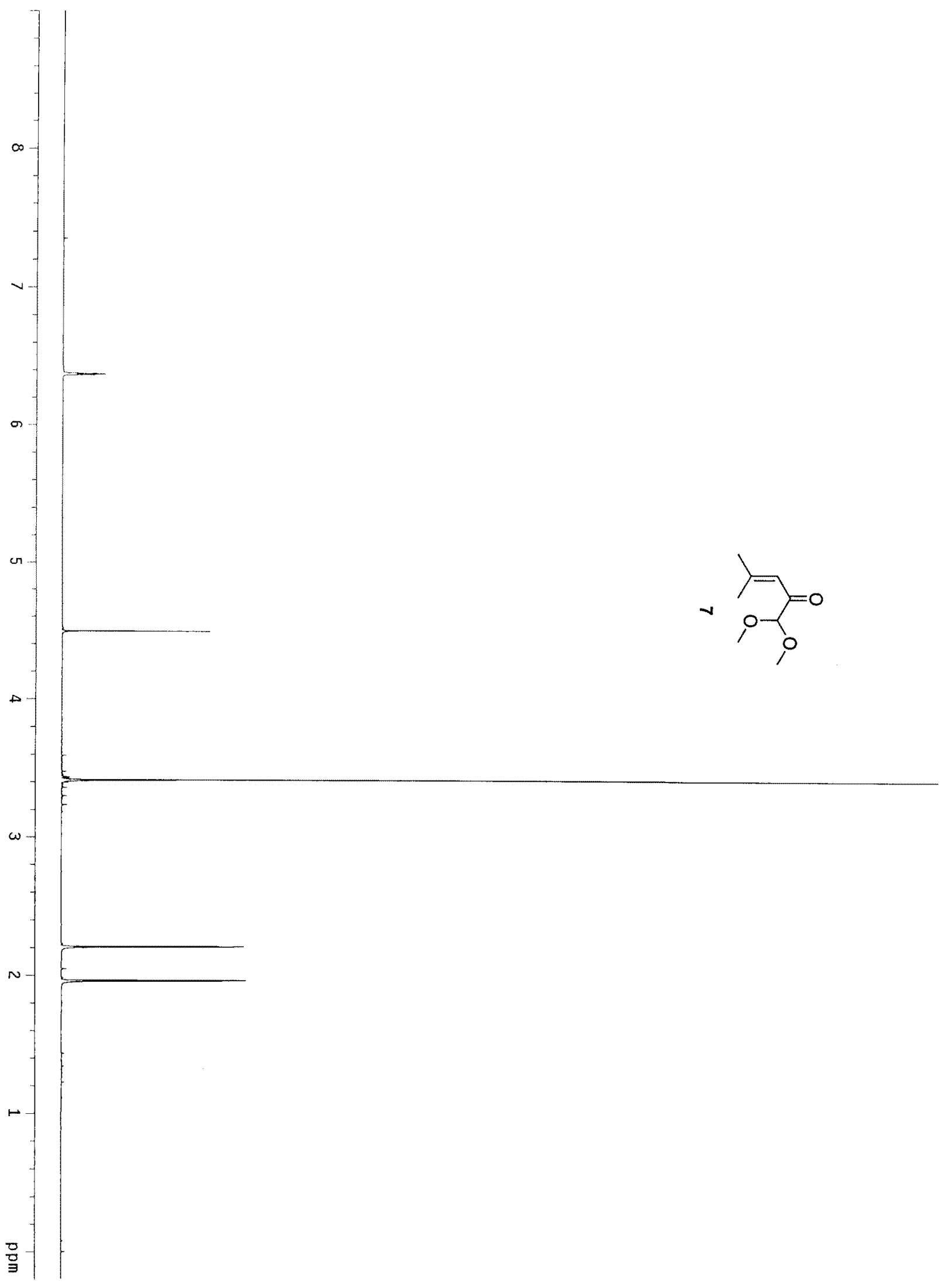




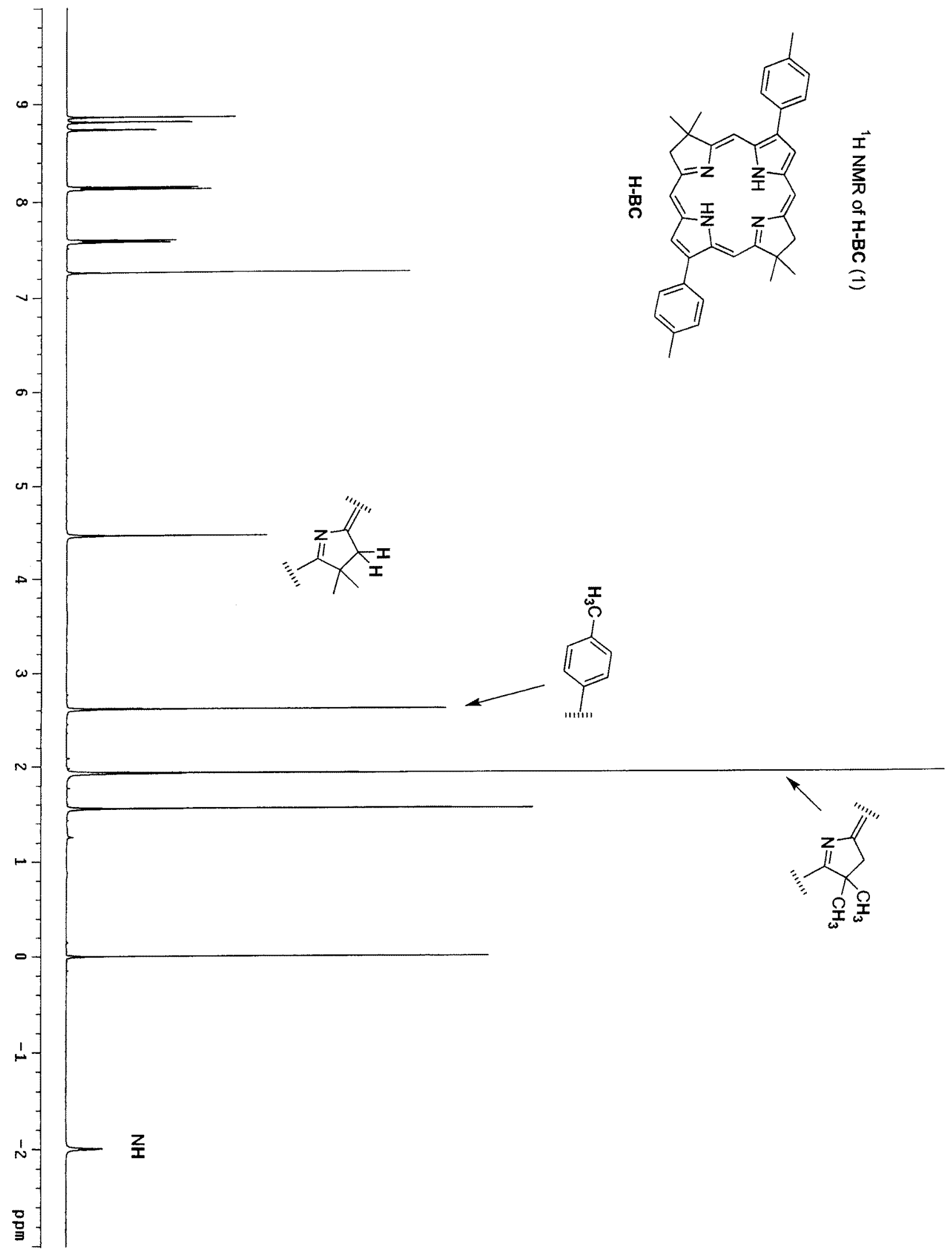




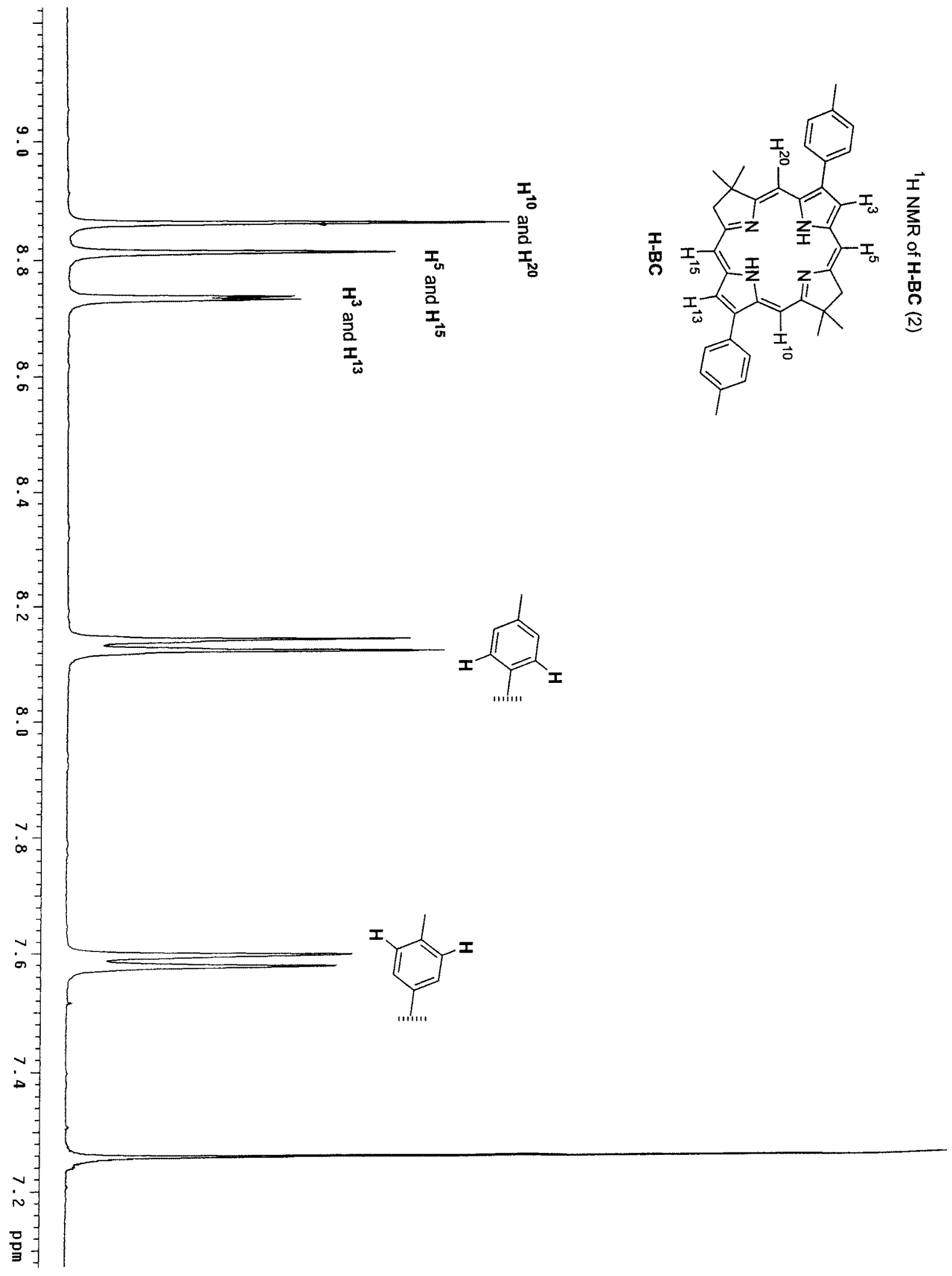



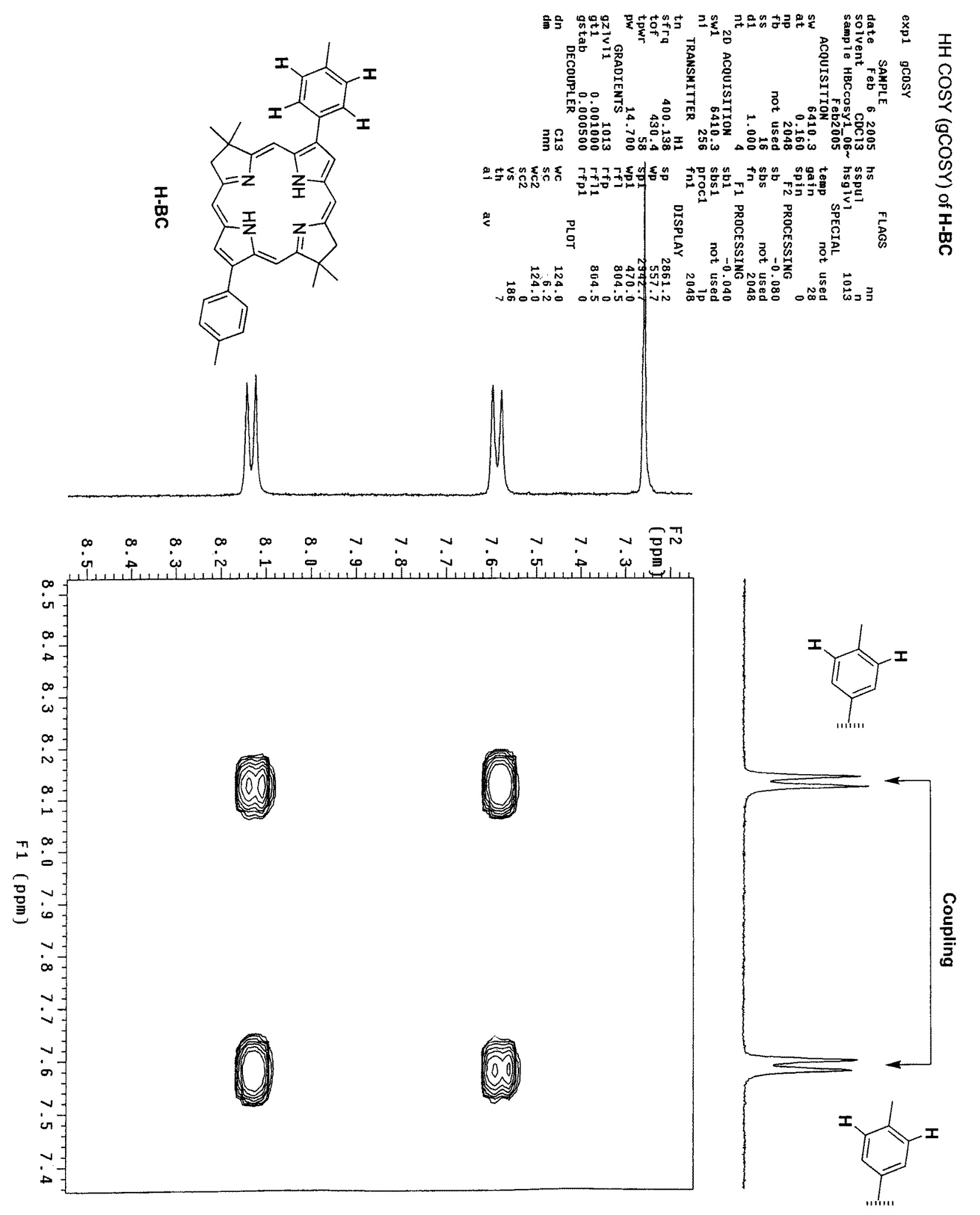

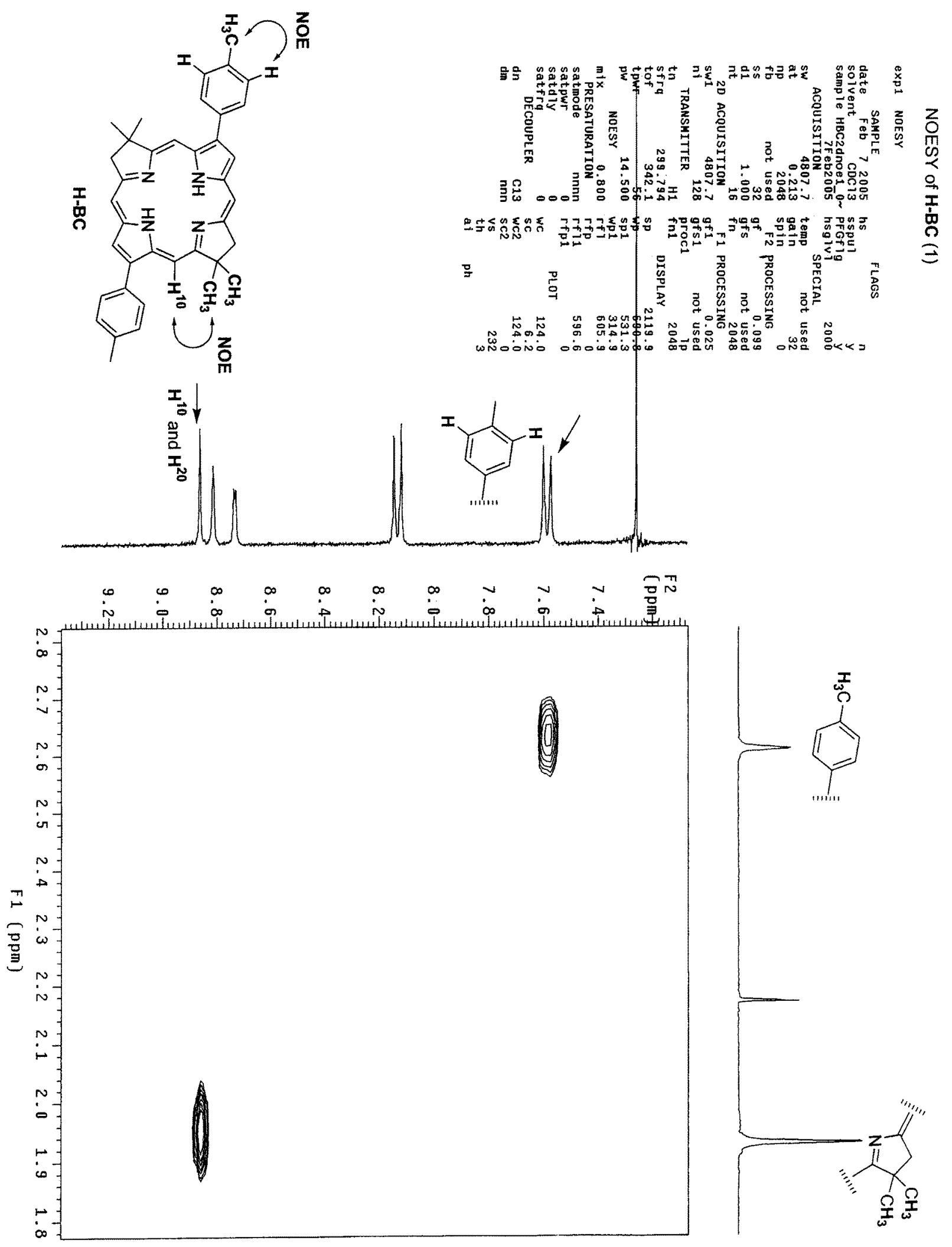

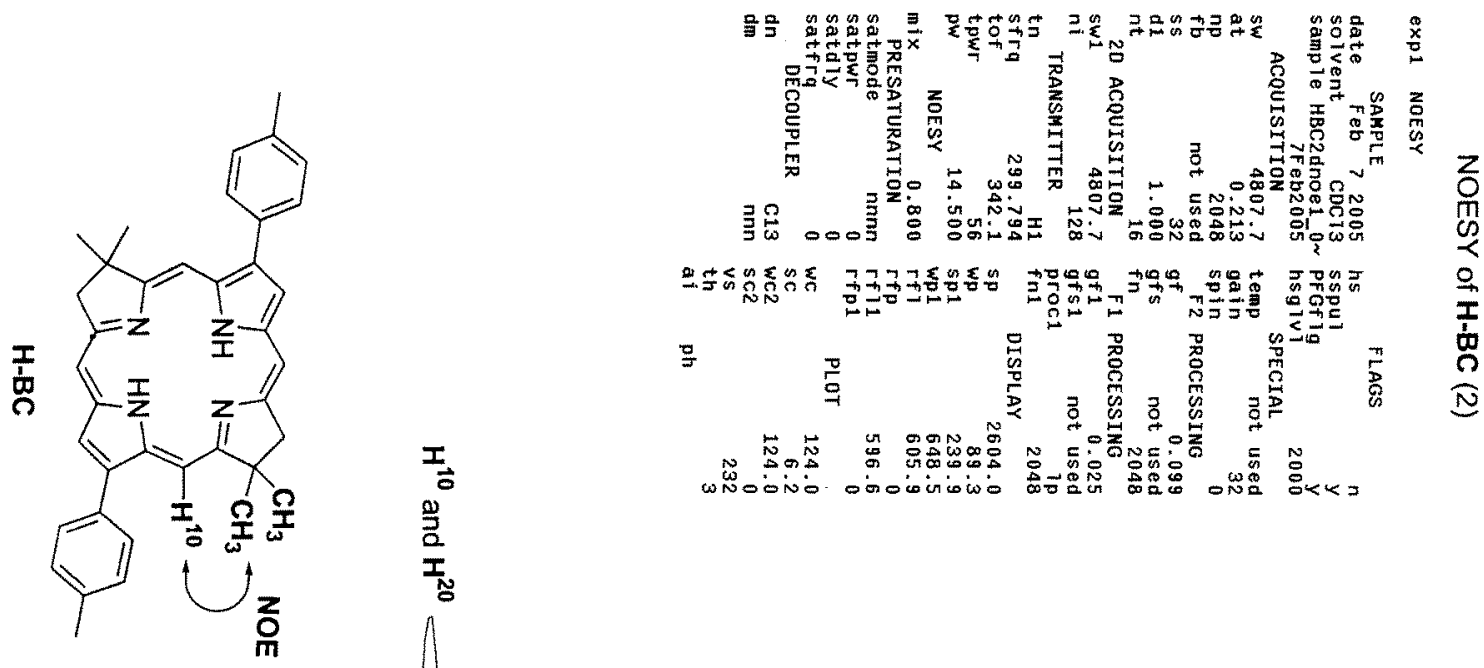

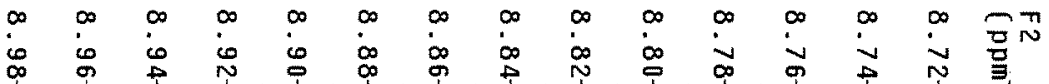

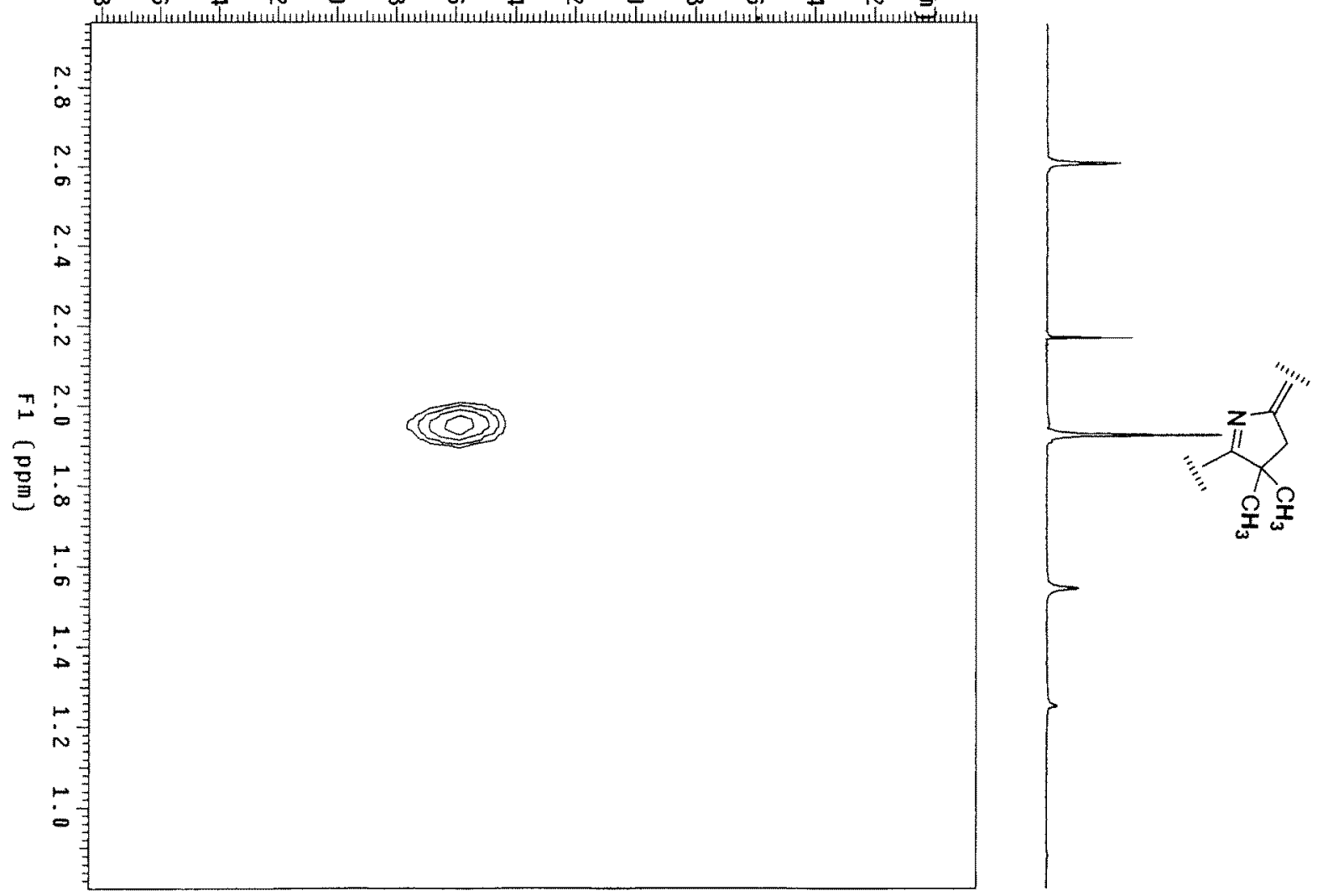



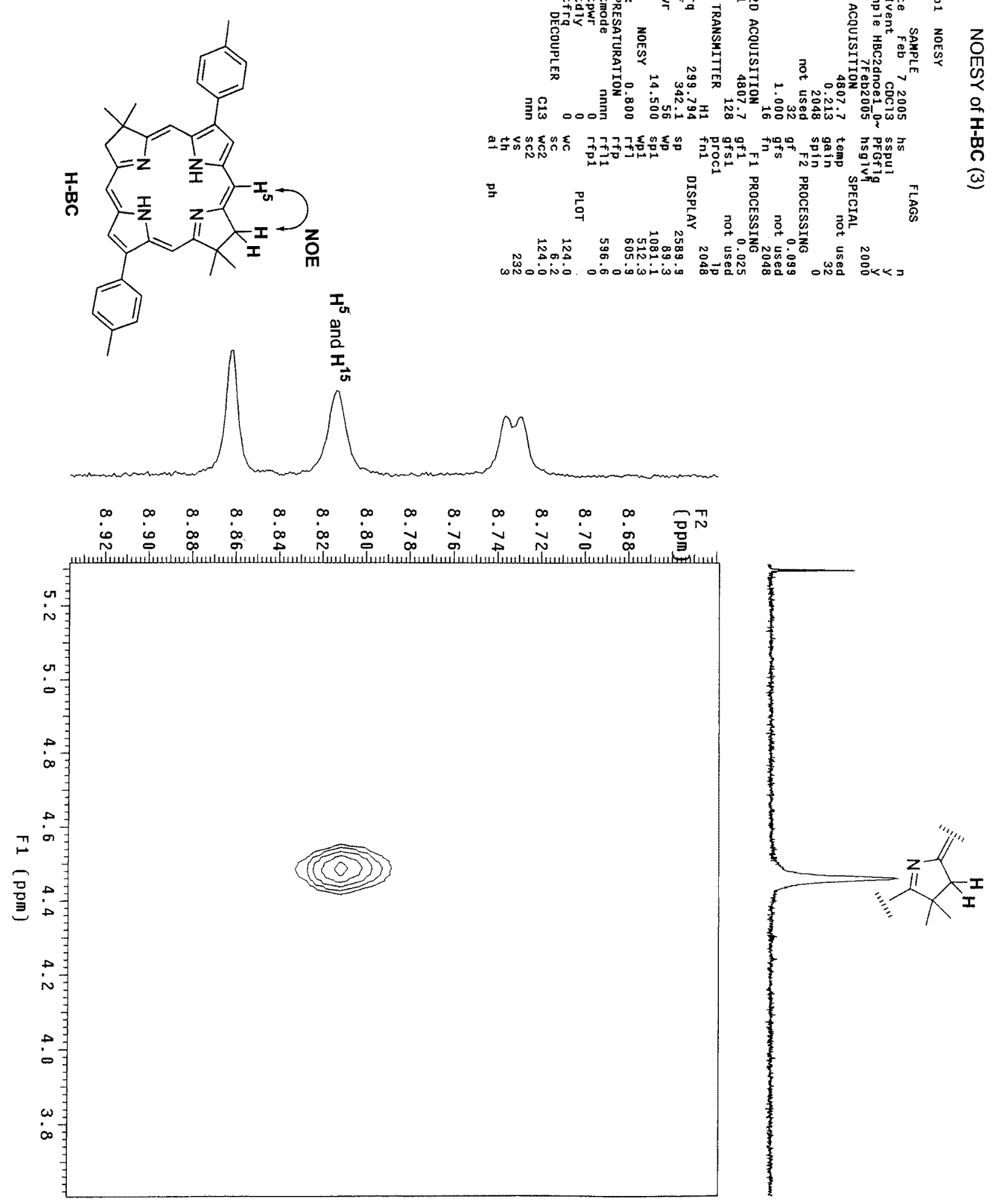


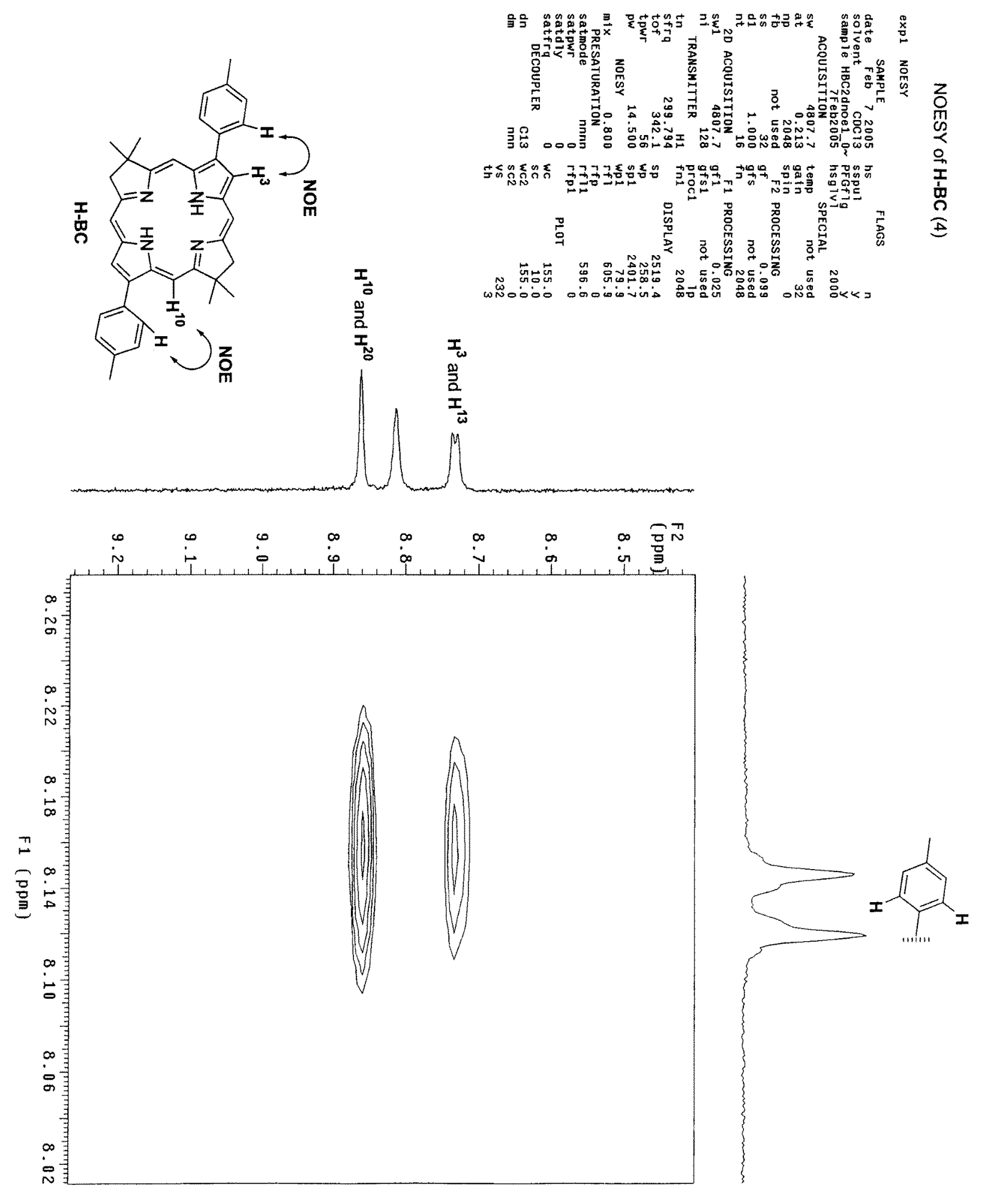




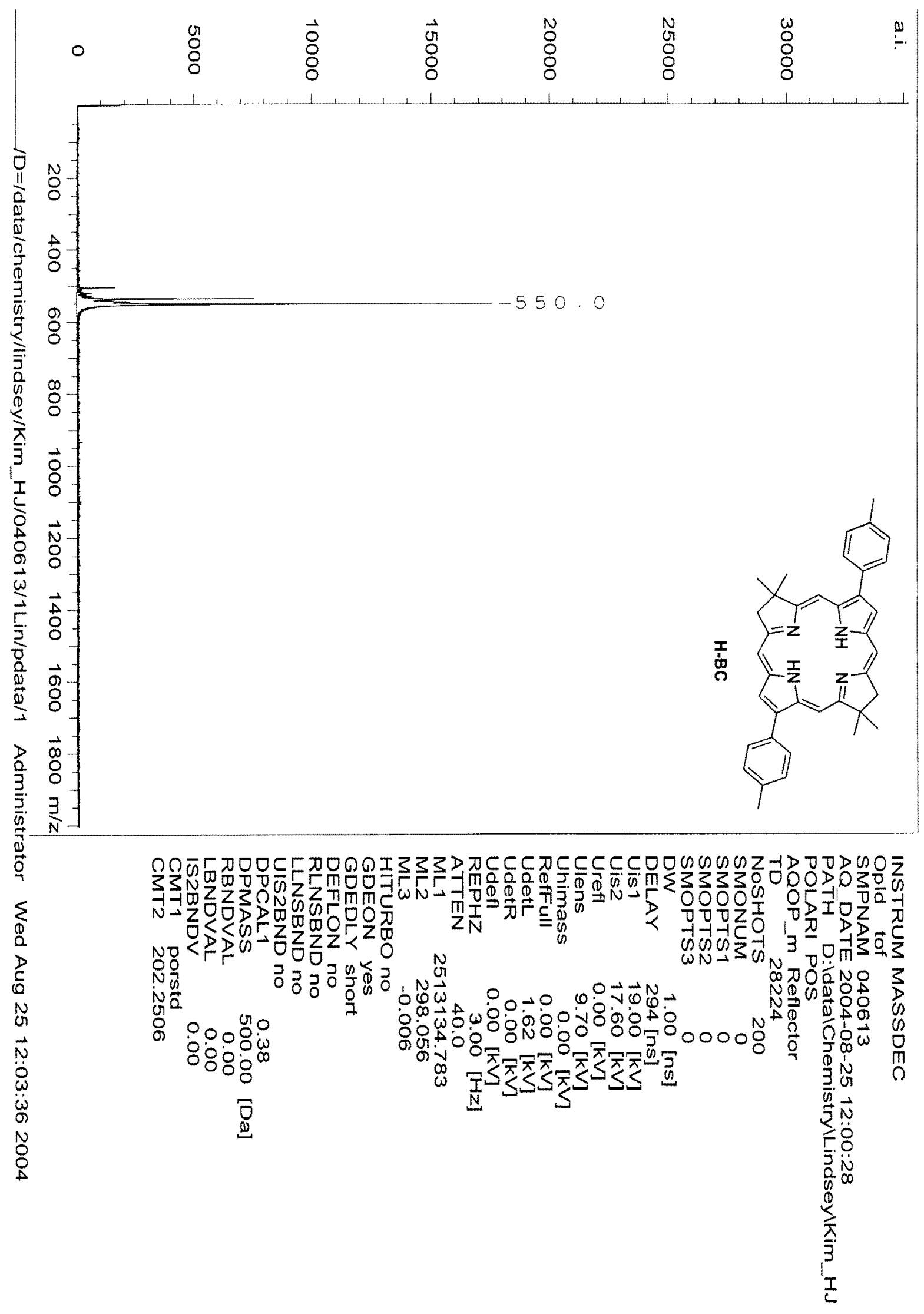




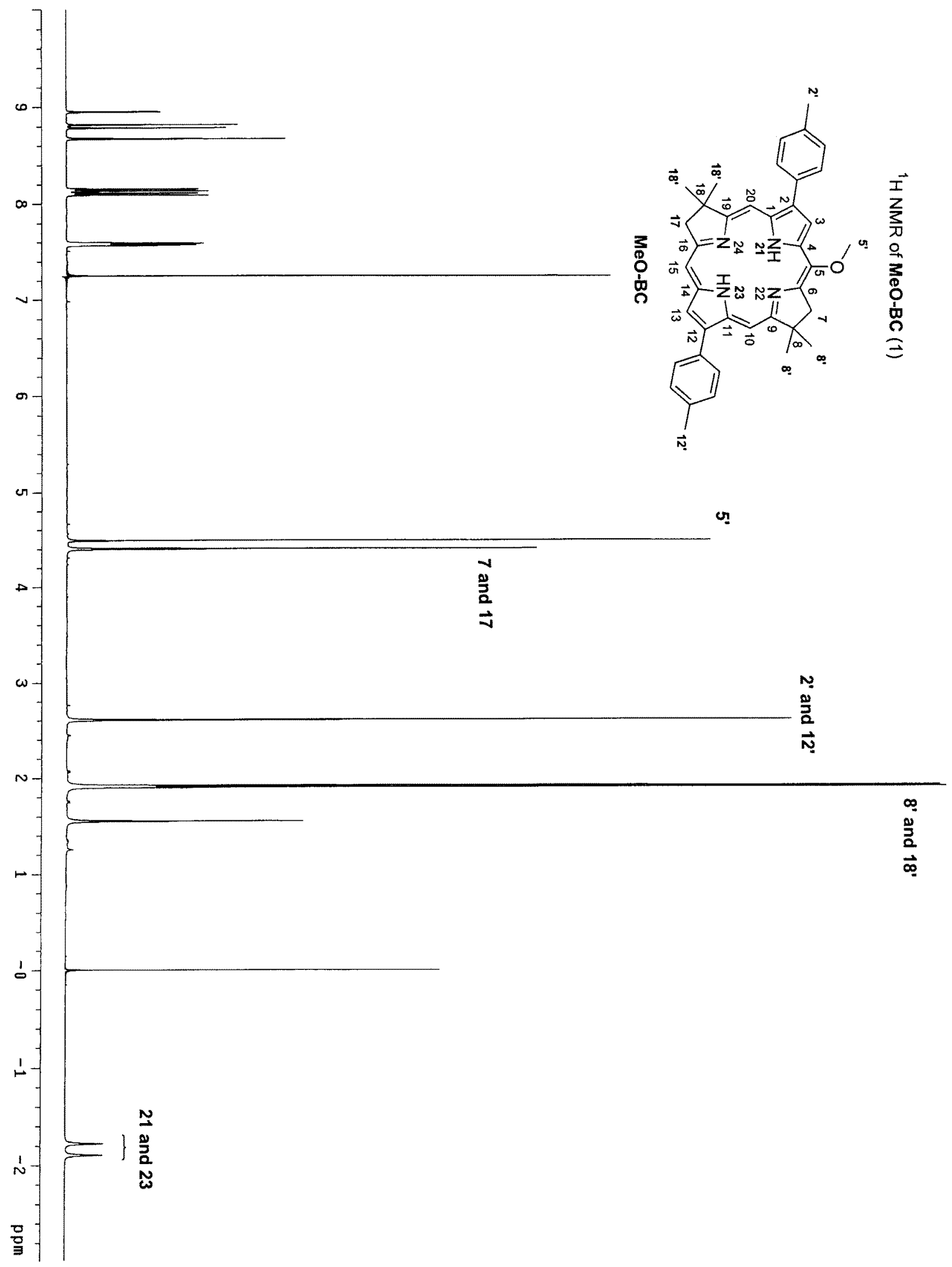




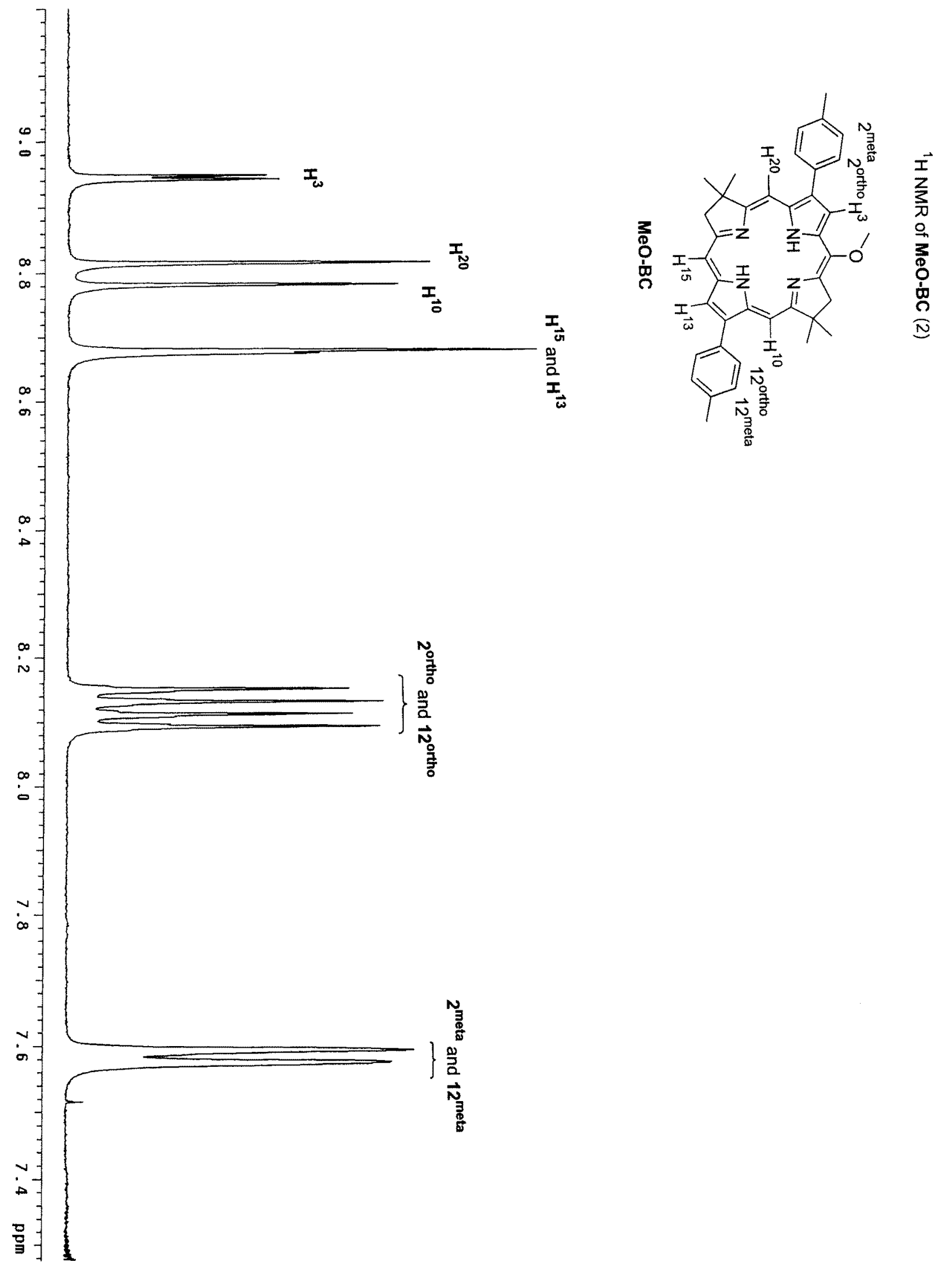



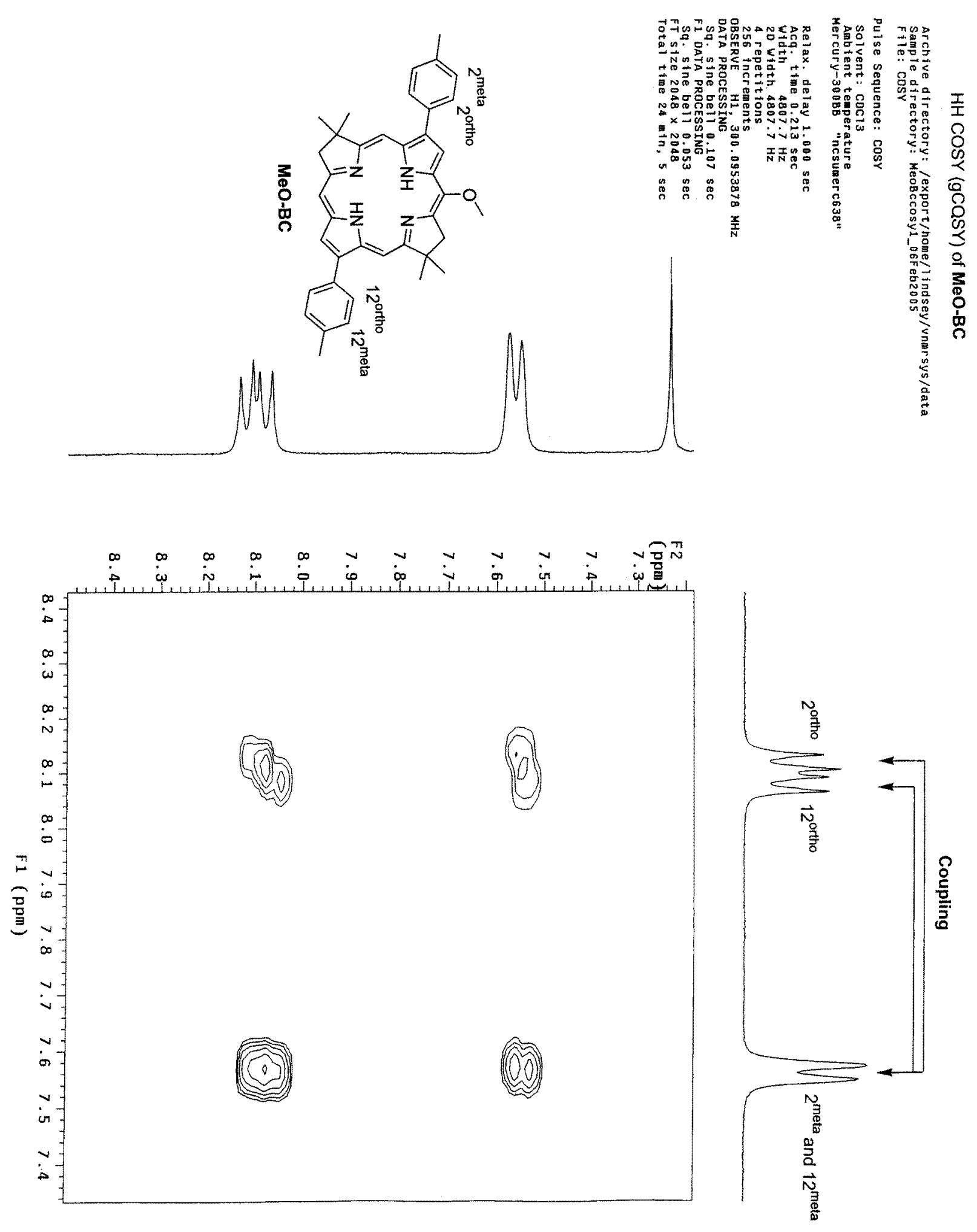

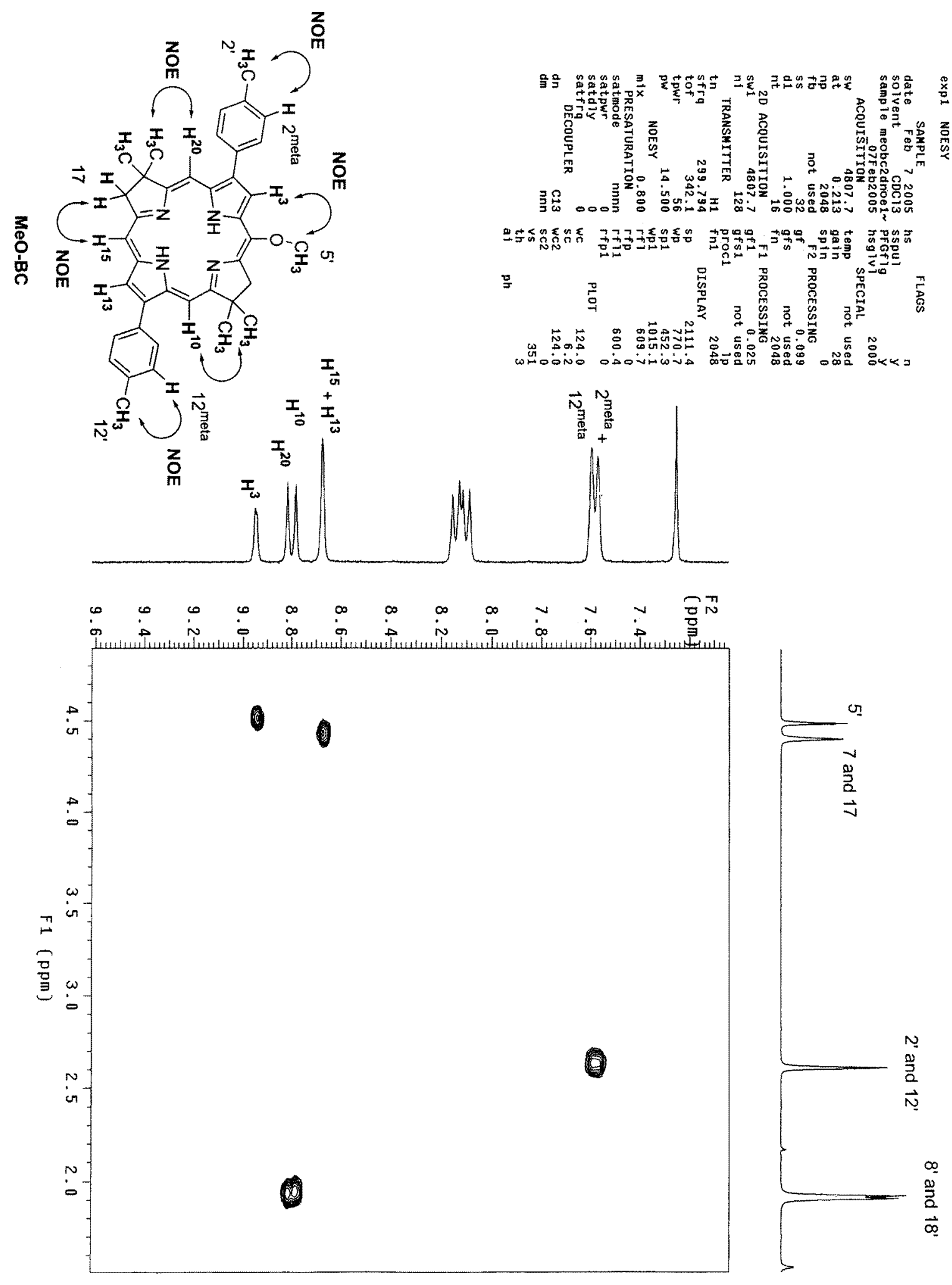


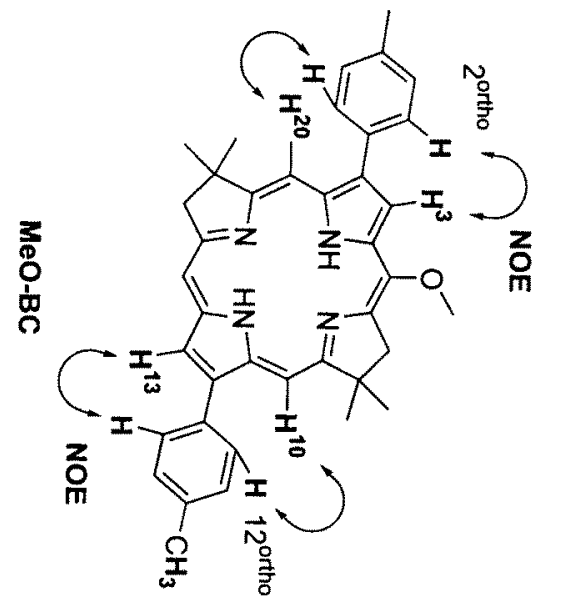

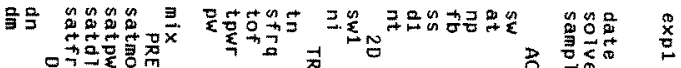

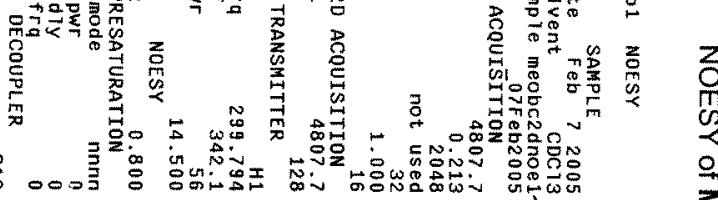

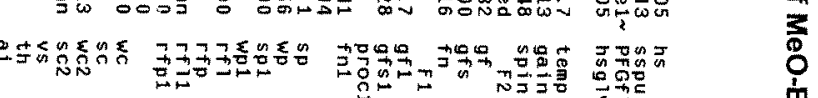

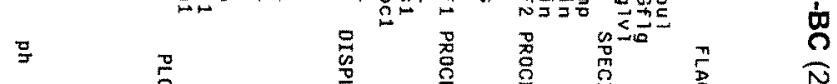

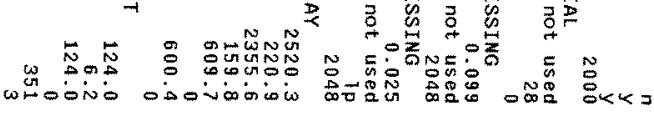

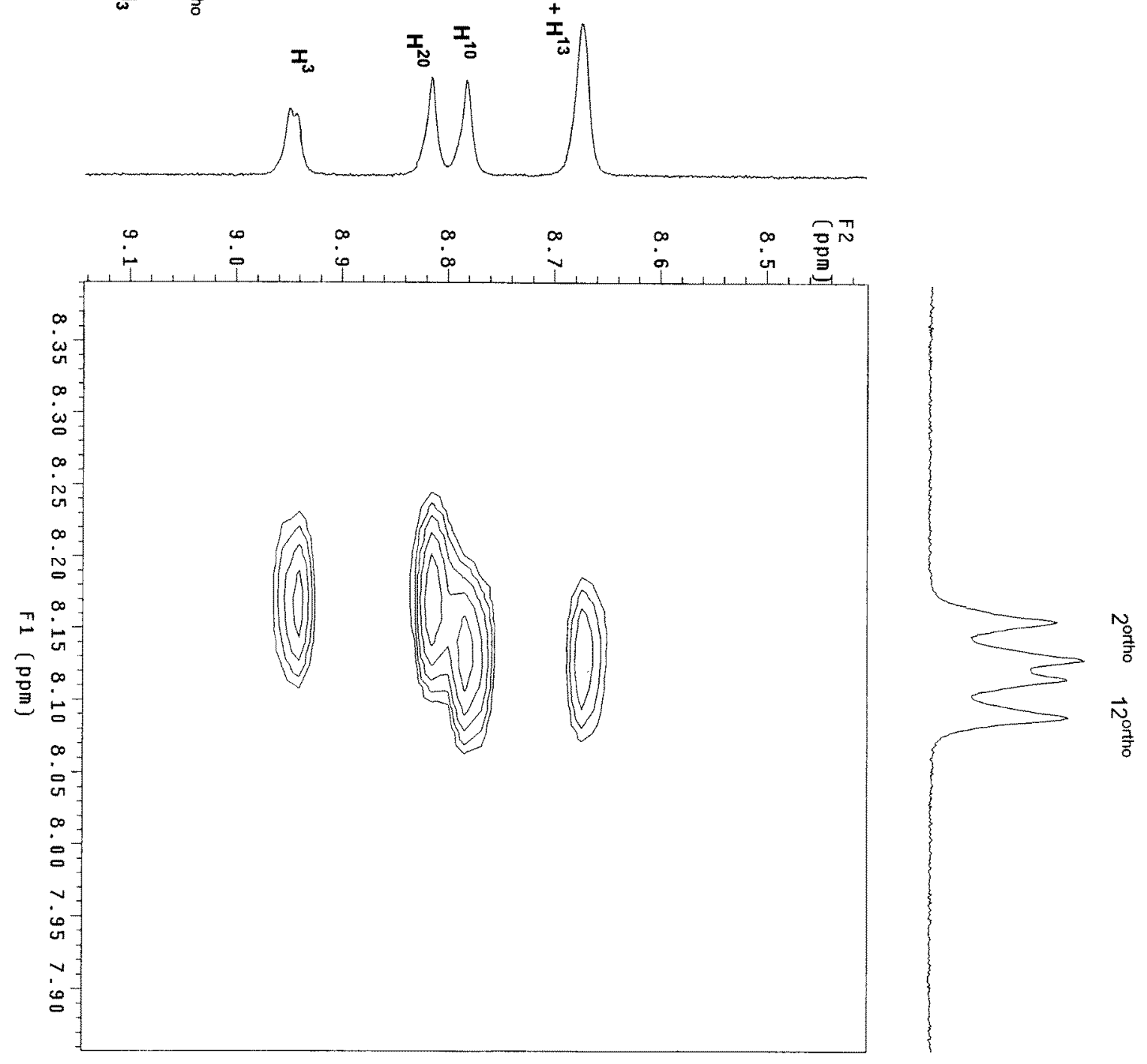




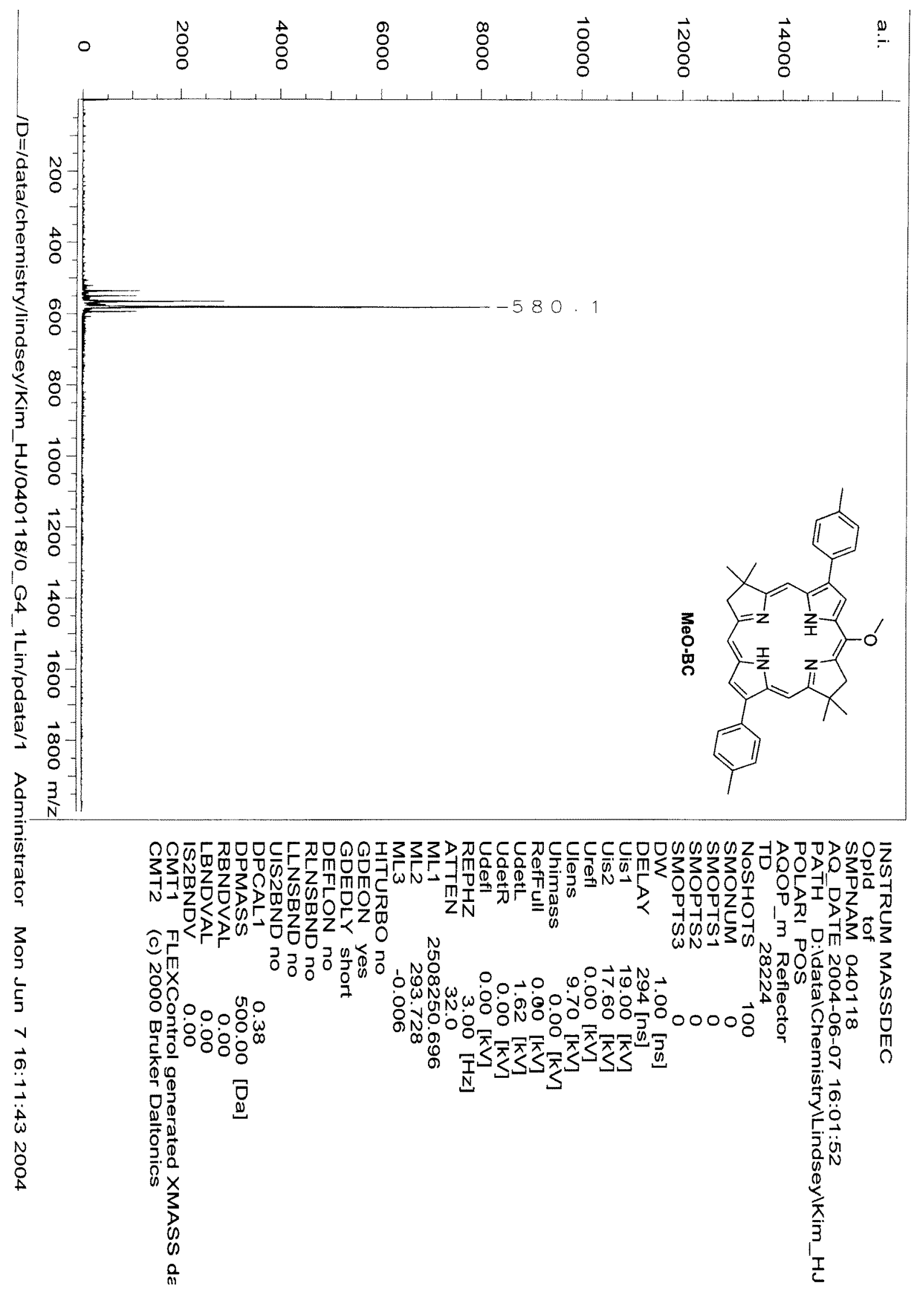




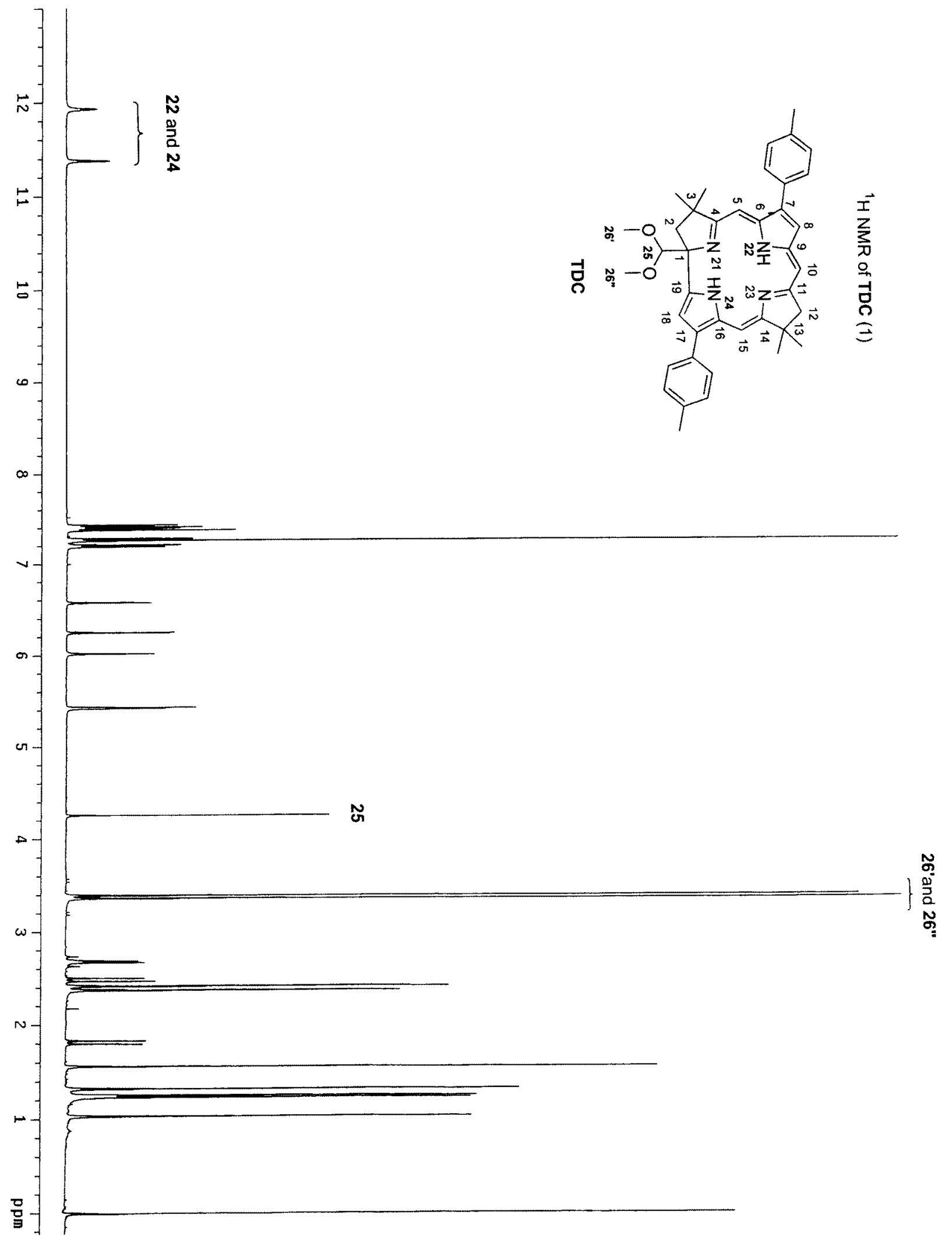




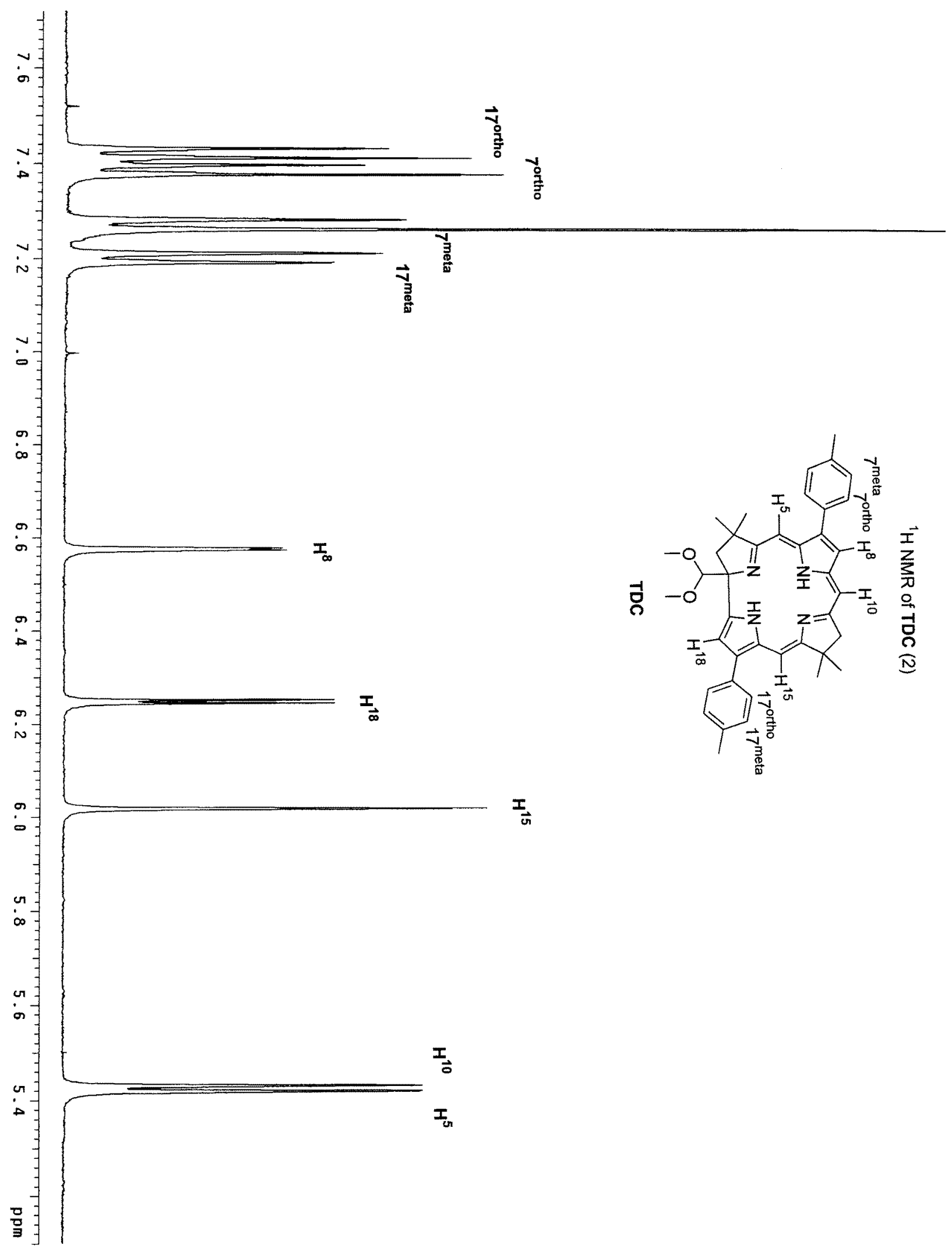




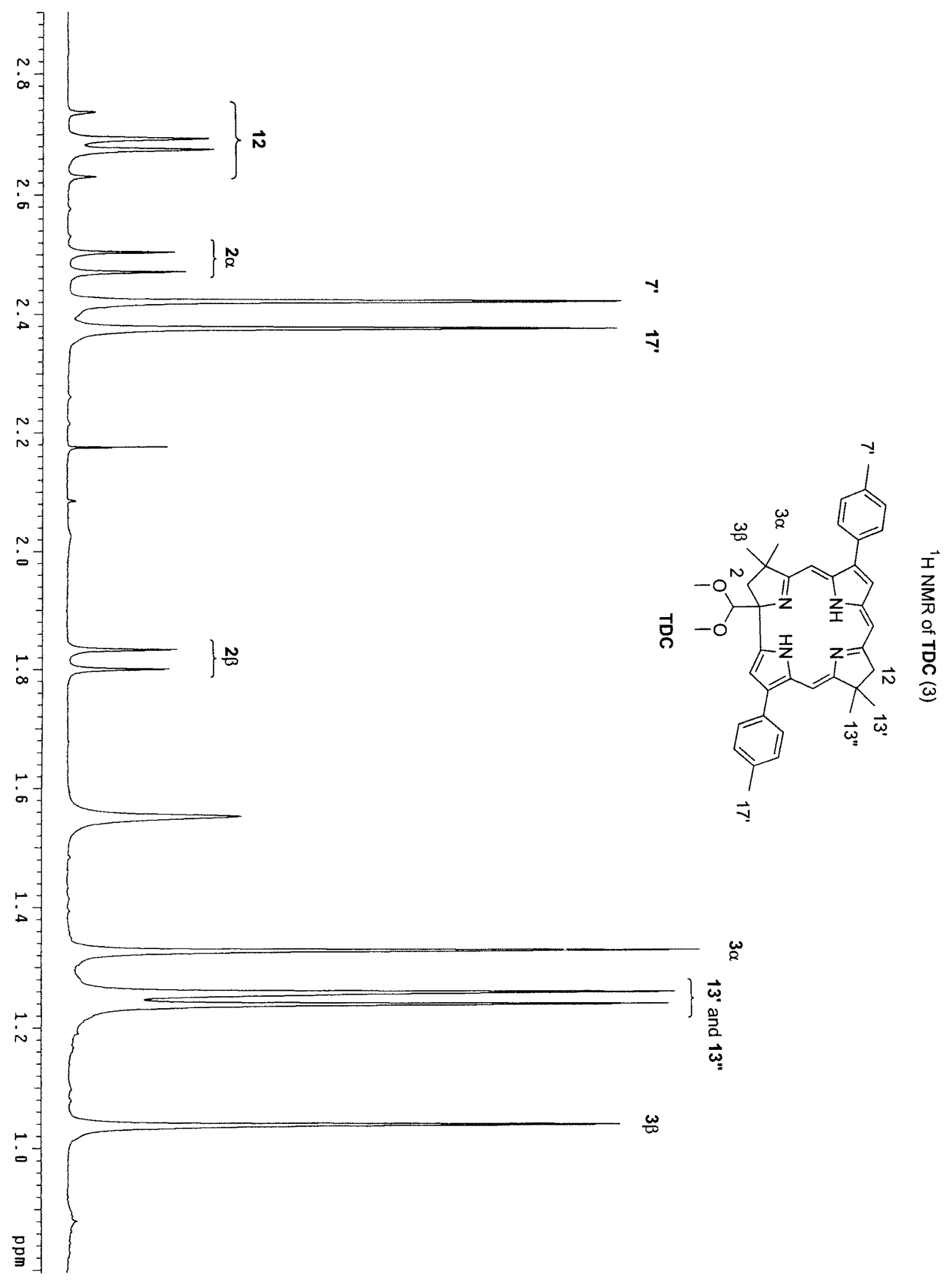




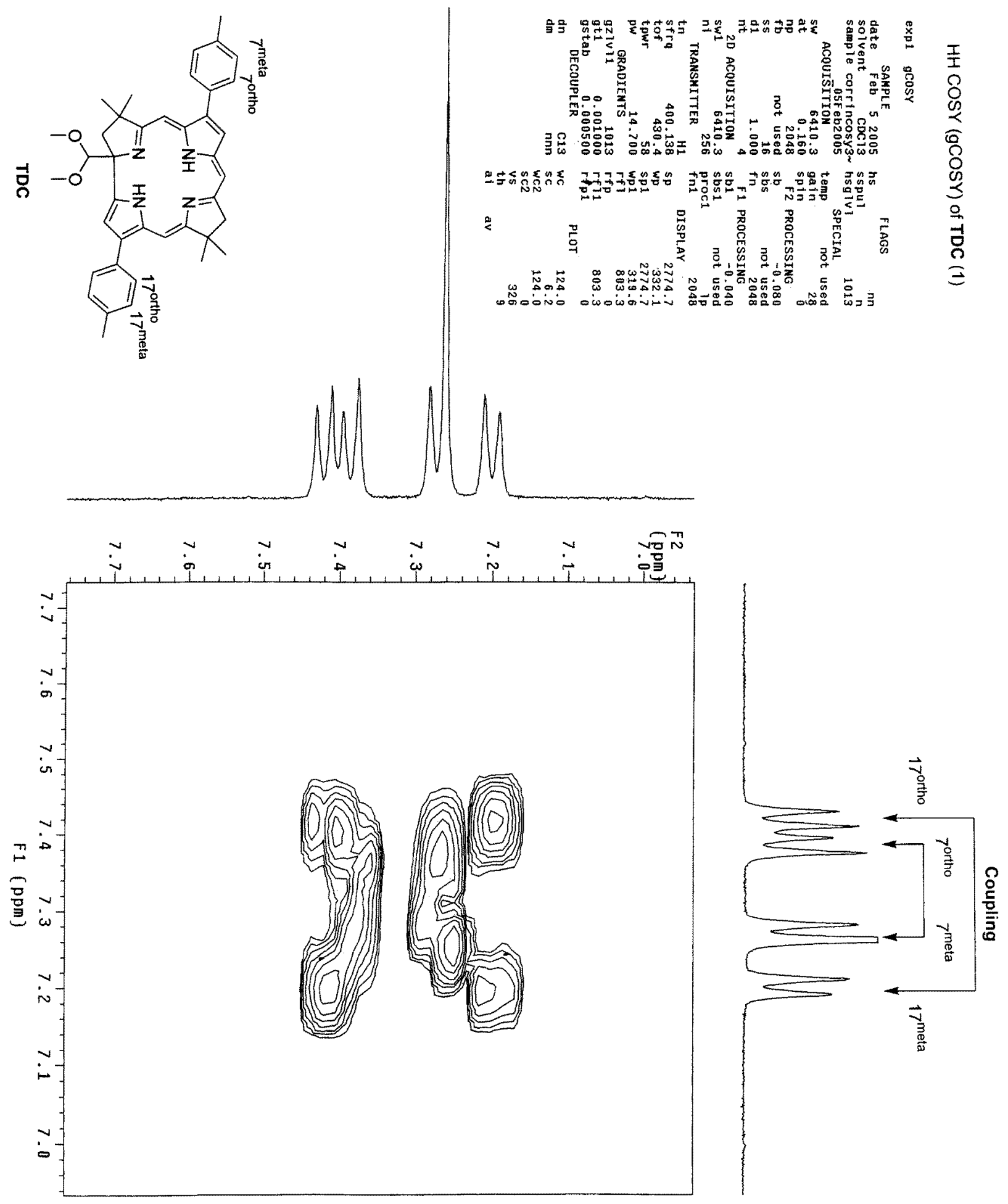



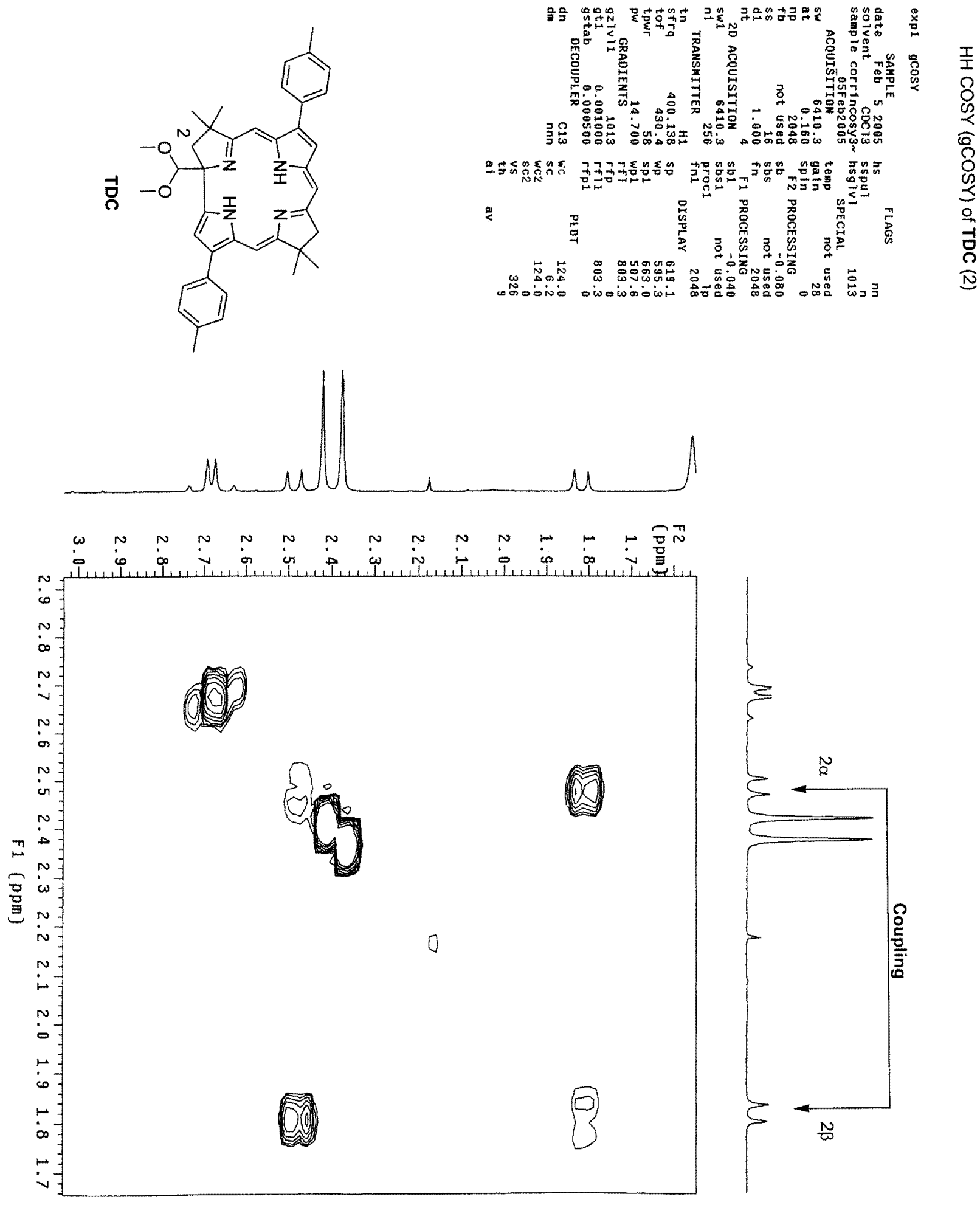

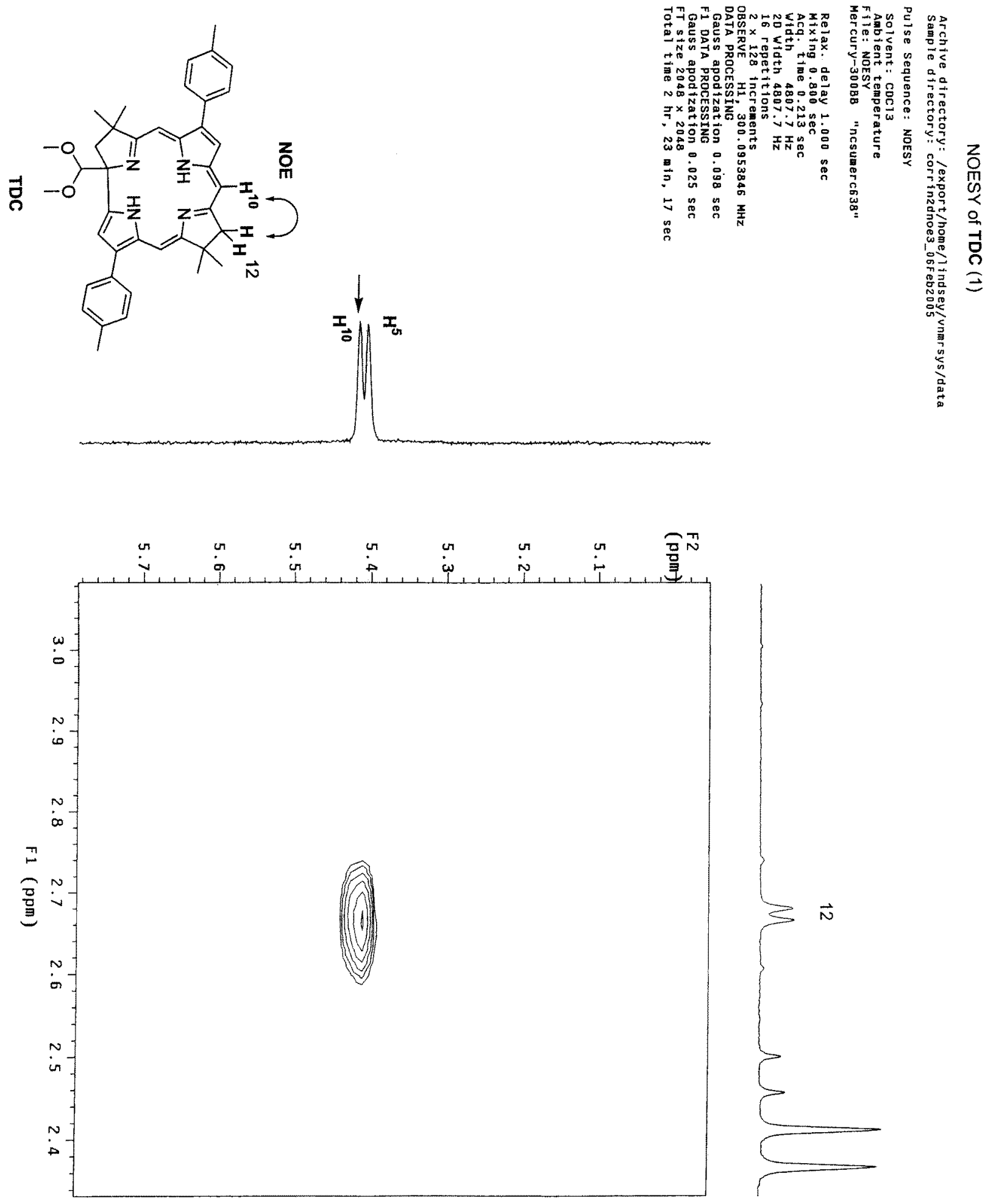

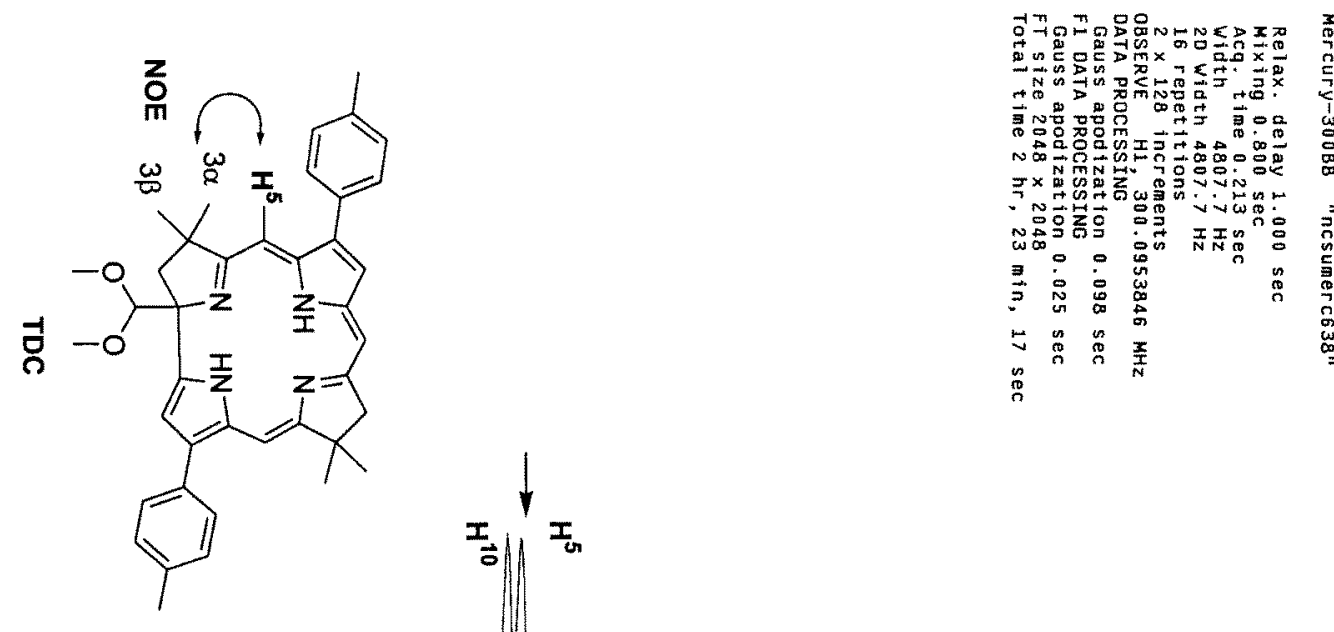

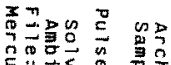

z

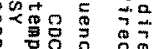

$=7$ " w

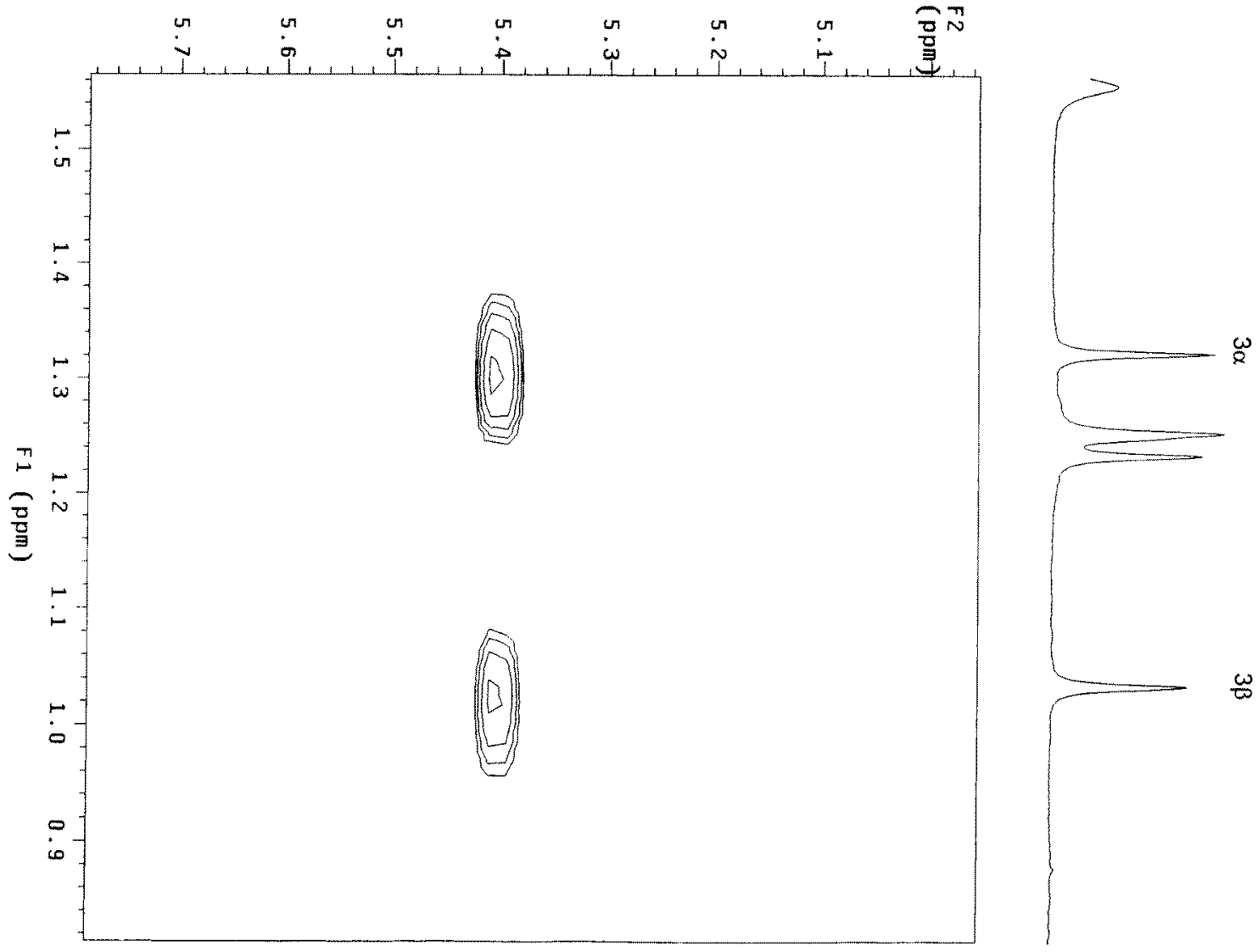



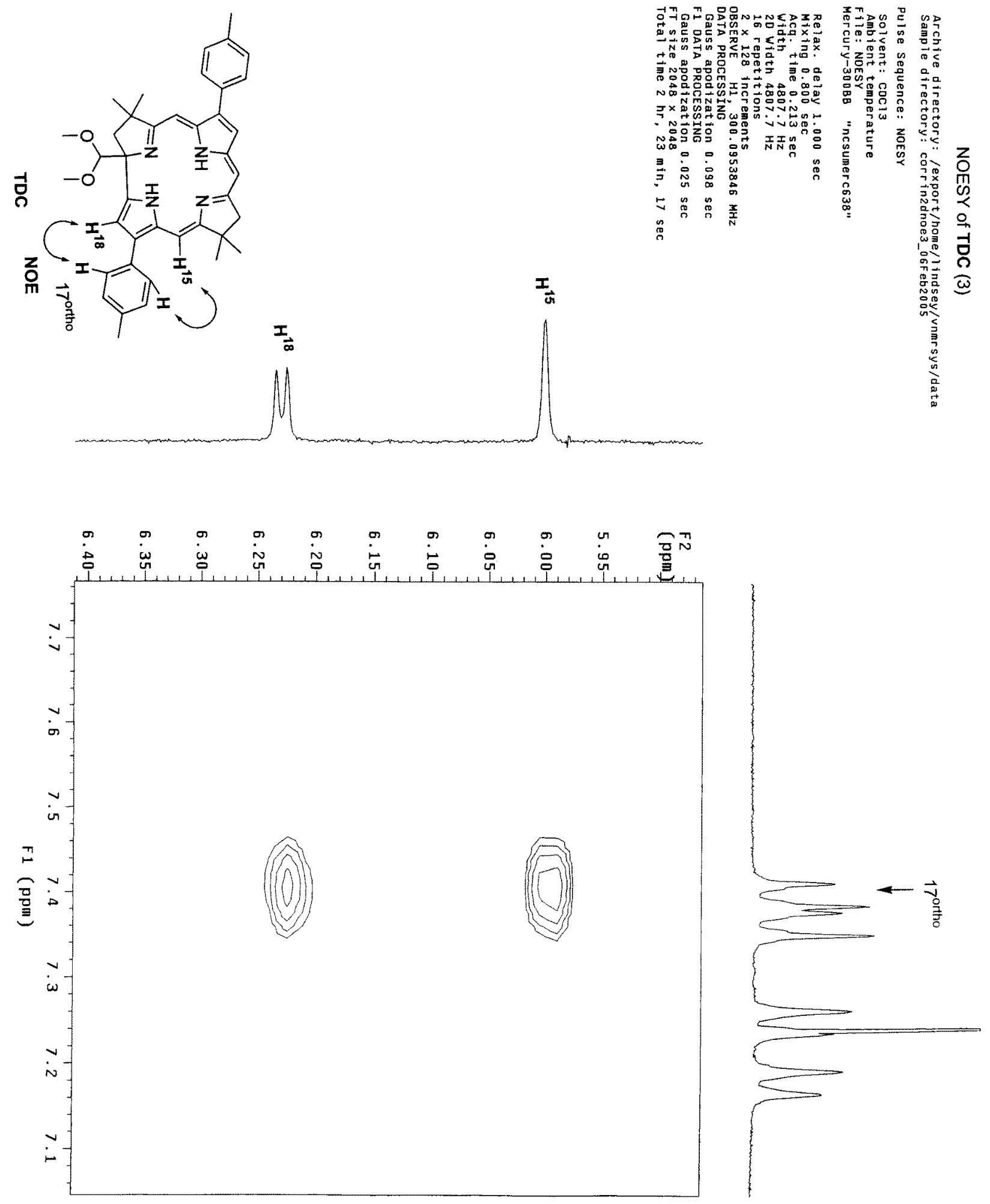

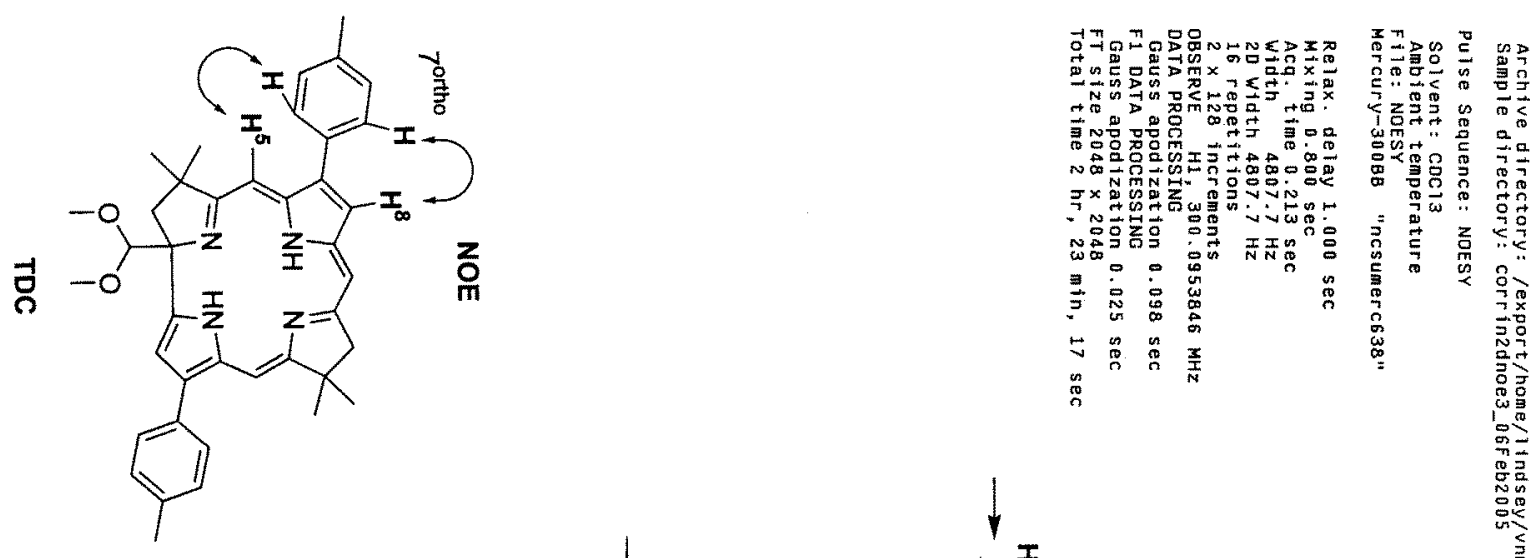

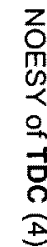
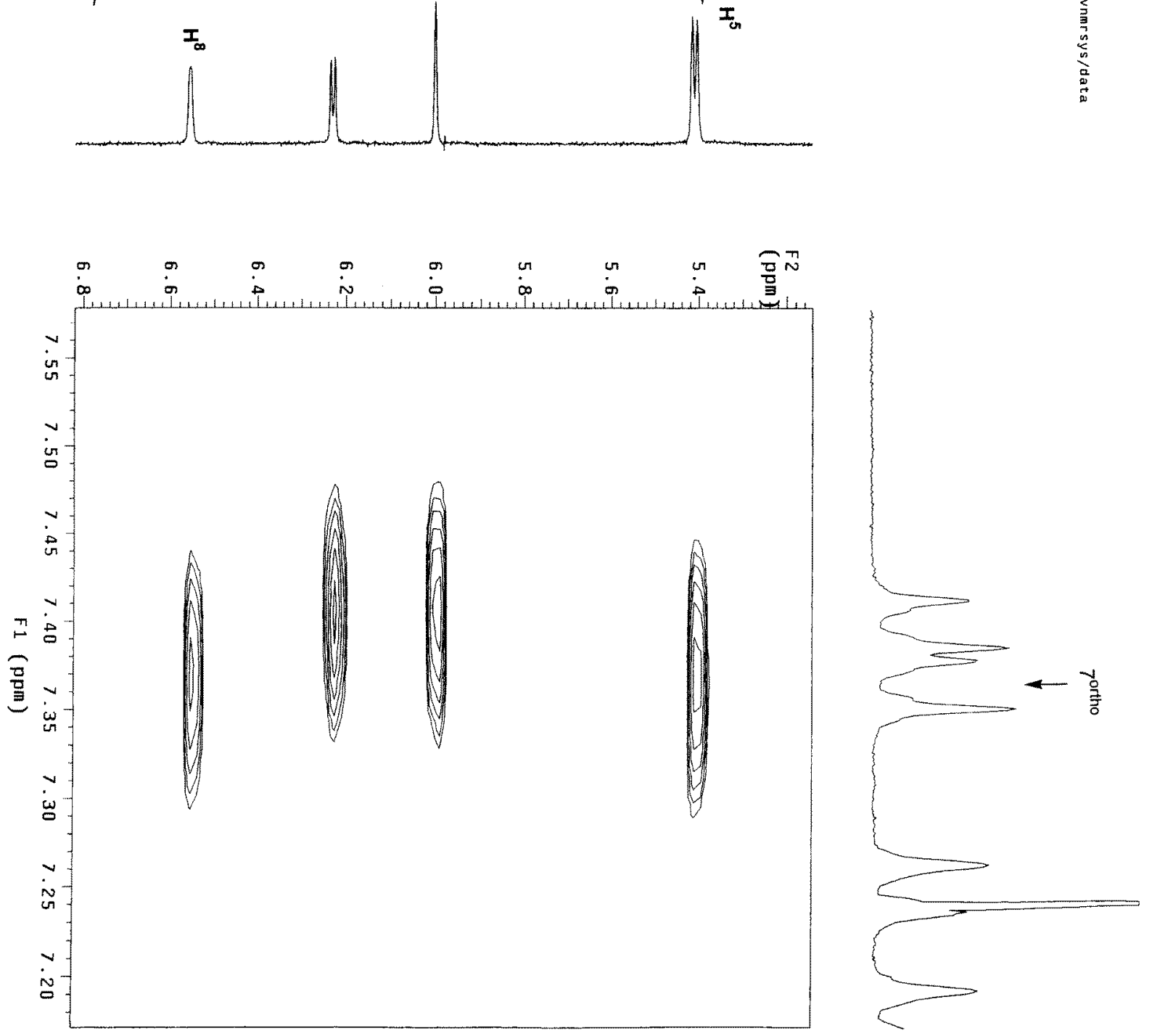

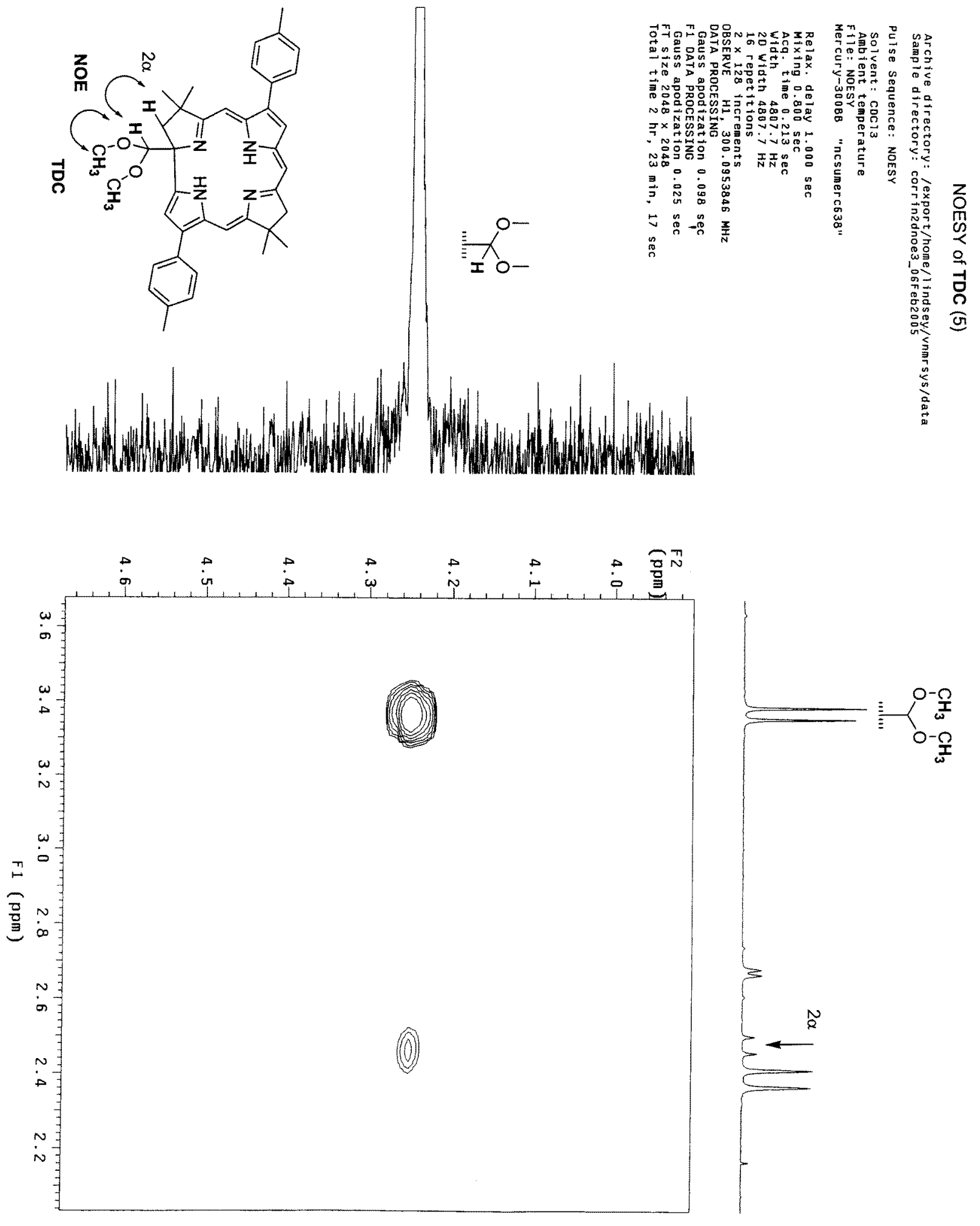

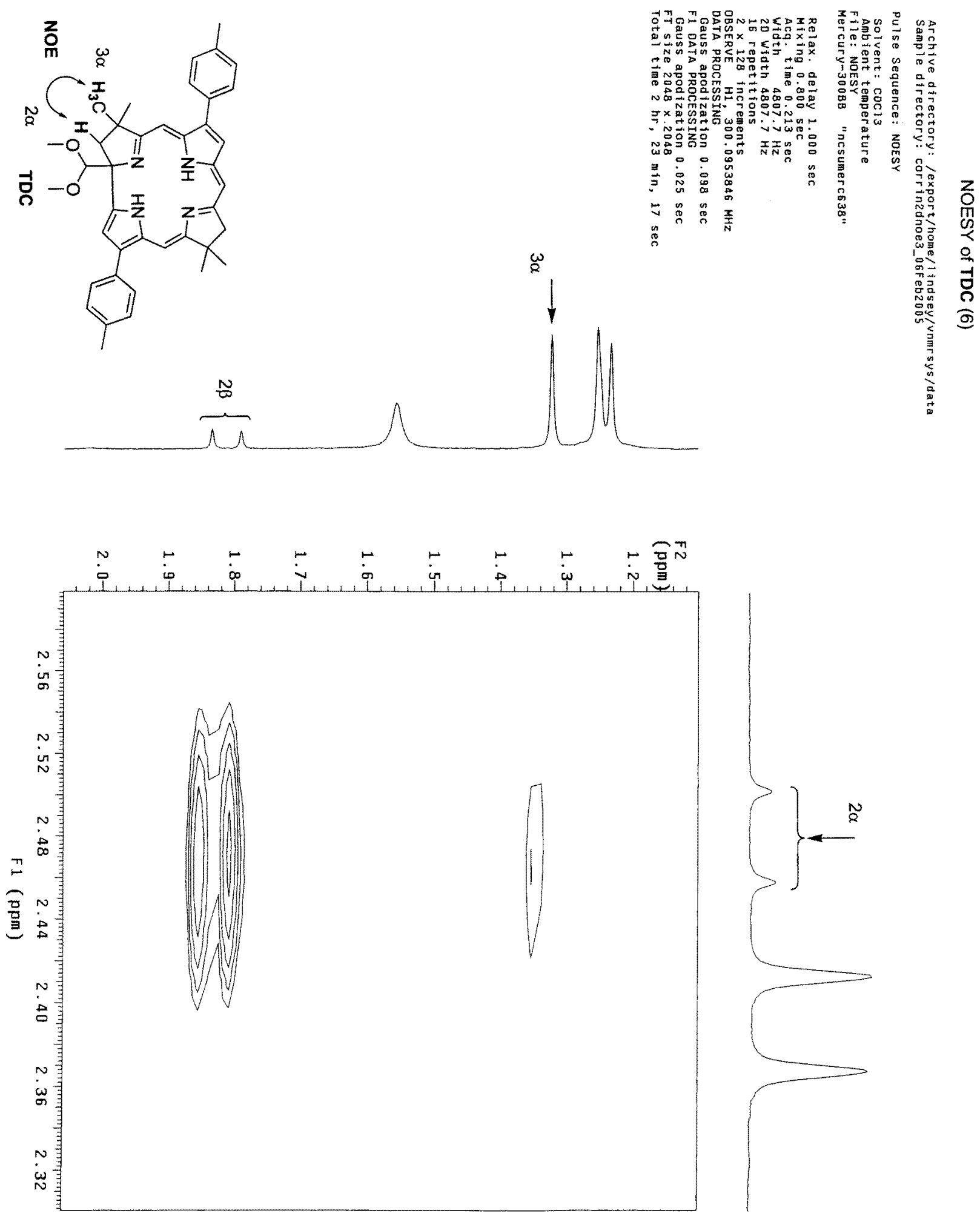


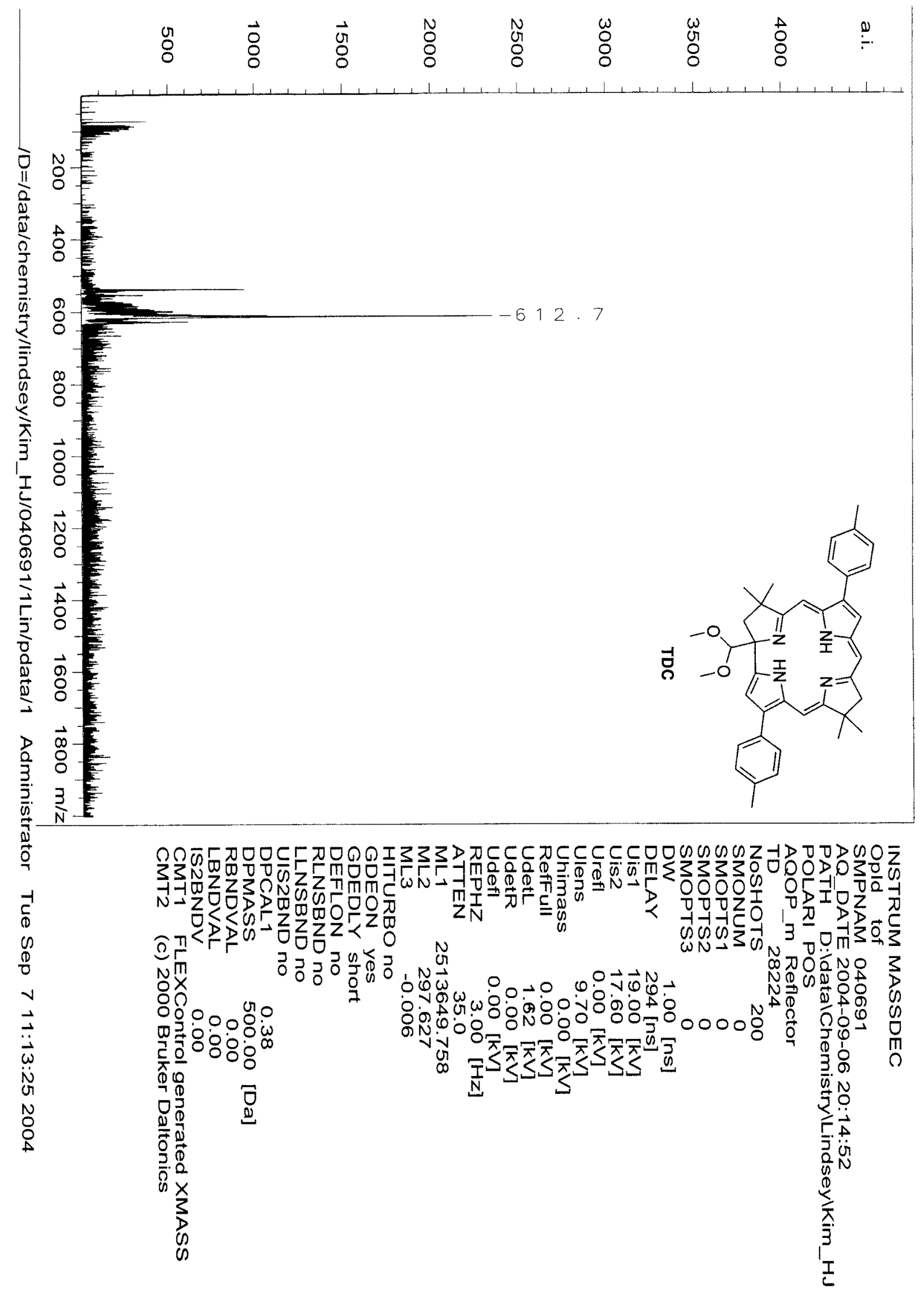

